Check for updates

Cite this: Phys. Chem. Chem. Phys., 2020, 22, 11943

Received 29th January 2020, Accepted 27th April 2020

DOI: $10.1039 / \mathrm{d} 0 \mathrm{cp} 00496 \mathrm{k}$

rsc.li/pccp

\title{
Tunable relativistic quasiparticle electronic and excitonic behavior of the $\mathrm{FAPb}\left(\mathrm{I}_{1-x} \mathrm{Br}_{x}\right)_{3}$ alloy
}

\author{
Zeeshan Muhammad, $\dagger^{\text {ab }}$ Peitao Liu, (D) $\dagger^{\mathrm{c}}$ Rashid Ahmad, ${ }^{\text {ad }}$ \\ Saeid Jalali Asadabadi, (D) ${ }^{\mathrm{e}}$ Cesare Franchini (D) *c and Iftikhar Ahmad ${ }^{\text {af }}$
}

\begin{abstract}
We study the structural, electronic, and excitonic properties of mixed $\mathrm{FAPb}\left(\mathrm{I}_{1-x} \mathrm{Br}_{x}\right)_{3} 0 \leq x \leq 1$ alloys by first-principles density functional theory as well as quasiparticle GW and Bethe Salpeter equation (BSE) approaches with the inclusion of relativistic effects through spin orbit coupling. Our results show that the system volume decreases with increasing $\mathrm{Br}$ content. The quasiparticle band gaps vary from $1.47 \mathrm{eV}$ for pure $\alpha-\mathrm{FAPbl}_{3}$ to $2.20 \mathrm{eV}$ for $\mathrm{Br}$-rich $\alpha-\mathrm{FAPbBr}_{3}$ and show stronger correlation with the structural changes. The optical property analysis reveals that the overall excitonic peaks are blue shifted with the $\mathrm{Br}$ fraction. Our results further reveal strong $\mathrm{Br}$ concentration dependence of the variation in the exciton binding energy (from 74 to $112 \mathrm{meV}$ ) and the carrier effective masses as well as the high frequency dielectric constants. These findings provide a way to tune the carrier transport properties of the material by doping, which could be utilized to improve the short circuit currents and power conversion efficiencies in multijunction solar cell devices.
\end{abstract}

\section{Introduction}

The growth in the human population and improvement of living standards across the globe have placed the search for efficient, economical and clean sources of renewable energy at the forefront of scientific research in the 21st century. An alternative to expensively processed silicon-based photovoltaics, hybrid organic-inorganic perovskites (HOIPs) having general formula $\mathrm{ABX}_{3}$ are a new class of low-cost, clean and efficient promising materials for affordable solar cell technologies. ${ }^{1-17}$ The rapid rise in power-conversion efficiencies within less than a decade increased the importance of such novel materials among the research community and hence these materials are progressively leading towards commercialization. The development of the revolutionary mixed type hybrid organic-inorganic perovskites has sparked much interest in the field of photovoltaics ${ }^{5,16-37}$ because of their low-cost compositional chemical management of constituents, allowing tailoring

\footnotetext{
${ }^{a}$ Center for Computational Material Science, University of Malakand, Chakdara, Pakistan

${ }^{b}$ Department of Physics, University of Malakand, Chakdara, Pakistan

${ }^{c}$ University of Vienna, Faculty of Physics and Center for Computational Materials Science, Sensengasse 8, A-1090 Vienna, Austria.

E-mail: cesare.franchini@univie.ac.at

${ }^{d}$ Department of Chemistry, University of Malakand, Chakdara, Pakistan

${ }^{e}$ Department of Physics, Faculty of Sciences, University of Isfahan,

HezarGerib Avenue, Isfahan 81744-73441, Iran

${ }^{f}$ Vice Chancellor, Gomal University, Dera Ismail Khan, Pakistan

$\dagger$ These authors contributed equally to this work.
}

of the electrical and optical parameters. Some of the key characteristics of these materials that make them exceptional are their tunable optimal band gap for appropriate sunlight absorption, 5,19-25,27-34,36 longer carrier lifetimes, 5,38,39 high charge carrier mobility, ${ }^{40-43}$ long charge carrier diffusion length $^{39,40,44}$ and weak exciton binding energy. ${ }^{45-52}$ The first reported material of this family was synthesized by Miyasaka et al. ${ }^{1}$ with a demonstrated solar cell efficiency of $3.8 \%$. Recently, Gharibzadeh et al. ${ }^{17}$ have attained an efficiency of $25.7 \%$ using a mixed-cation lead mixed-halide perovskite/Si heterojunction in a tandem solar cell. The prominent feature of a tandem solar cell is that it uses two or more semiconducting layers, which absorb different parts of sunlight, yielding low thermalization losses and high-power conversion efficiencies (PCEs) as compared to single junction solar cells. ${ }^{53}$

According to recent studies, progress in the efficiency and chemical stability of perovskite based solar cells can be accomplished by the compositional chemical management of the A site having larger cations like cesium $\left(\mathrm{Cs}^{+}\right)$, methylammonium MA $\left(\mathrm{CH}_{3} \mathrm{NH}_{3}{ }^{+}\right)$and formamidinium $\mathrm{FA}\left(\mathrm{CH}\left(\mathrm{NH}_{2}\right)_{2}\right)^{+},{ }^{25-27,30,54}$ of the $\mathrm{B}$ site having smaller divalent inorganic cations e.g. $\mathrm{Pb}^{2+}$ and $\mathrm{Sn}^{2+}, 32,33,55$ and of the $\mathrm{X}$ site containing monovalent metal halides including $\mathrm{I}^{-}, \mathrm{Br}^{-}$and $\mathrm{Cl}^{-}{ }^{18,19,22,28,29,36,37,56,57}$ For example, gradual substitution of the FA cation in $\mathrm{MAPbI}_{3}$ will reduce the band gap from $1.57 \mathrm{eV}$ to $1.48 \mathrm{eV},{ }^{30,58}$ thus yielding improved transport properties, ${ }^{59}$ long photoluminescence (PL) lifetimes, ${ }^{60}$ and lower recombination and device hysteresis with high PCEs. ${ }^{19,61,62}$ Similarly, slowly replacing the $\mathrm{Pb}^{2+}$ cation with less toxic $\mathrm{Sn}^{2+}$ at the B site will vary the band gap between $1.51 \mathrm{eV}$ and 
$1.28 \mathrm{eV}^{55}$ The rapid oxidation of $\mathrm{Sn}^{2+}$ to $\mathrm{Sn}^{4+}$ especially in $\mathrm{SnI}_{2}$ and precursor solutions leads to high defect densities and short carrier diffusion lengths, which restricts its widespread use because of low PCEs. ${ }^{63,64}$ In order to have a wide range of variations in the electronic as well as in the optical properties, the mixing of metal halides at the $\mathrm{X}$ site provides an effective way to give such a fine-tuning property suitable for designing and improving the performance of multijunction solar cell devices. In addition to $\operatorname{MAPb}\left(\mathrm{I}_{1-x} \mathrm{Cl}_{x}\right)_{3}{ }^{18,56}$ and $\mathrm{MAPb}\left(\mathrm{I}_{1-x} \mathrm{Br}_{x}\right)_{3},{ }^{28,36,37,57}$ $\mathrm{FAPb}\left(\mathrm{I}_{1-x} \mathrm{Br}_{x}\right)_{3}{ }^{19,22,29}$ has also been successfully synthesized and demonstrated in solar cells. To date mixed hybrid perovskites containing the $\mathrm{FAPb}\left(\mathrm{I}_{1-x} \mathrm{Br}_{x}\right)_{3}$ system have achieved the highest efficiency so far in perovskite based solar cells. ${ }^{17}$

Although the $\operatorname{FAPb}\left(\mathrm{I}_{1-x} \mathrm{Br}_{x}\right)_{3}$ alloy has been experimentally studied, a thorough in-depth theoretical description and understanding of the structural parameters, electronic density of states (DOS), band gaps, carrier excitations and exciton binding energies has not been fully addressed. In the present work, the $\mathrm{FAPb}\left(\mathrm{I}_{1-x} \mathrm{Br}_{x}\right)_{3}$ system is studied with density functional theory (DFT), which proves to be a powerful tool for modeling and simulations of materials. ${ }^{65,66}$ The commonly used generalized gradient approximation (GGA) of Perdew-Burke-Ernzerhof $(\mathrm{PBE})^{67,68}$ provides structural lattice parameters close to the experimental values, but it is well known that DFT fails to describe the excited state properties such as quasiparticle (QP) band gaps and excitonic properties. ${ }^{69,70}$ An additional complication in relativistic HOIPs is the need to include spin-orbit coupling (SOC) effects, which causes further reduction of the bandgaps. ${ }^{46,71-77}$ Moreover, the use of hybrid functionals like HSE06 including SOC does not satisfactorily improve the issue of band gap underestimation. ${ }^{76}$ The state-of-the-art approach to improve the band gap is the GW method, ${ }^{78,79}$ which provides a good approximation in evaluating the self-energy operator as contraction of the one-body Green's function (G) with the screened Coulomb interaction (W). The GW method has been widely used for many systems ranging from elemental semiconductors ${ }^{69,70,80}$ to HOIPs, ${ }^{46,71,72,74-77,81}$ yielding band gaps in better agreement with experiments.

Since during the optical excitation the interactions of the electron-hole pairs create excitons which strongly couple to the incoming photons, this leads to substantial modification of the optical spectrum both below and above the quasiparticle band gaps. To explore the excitonic peaks in the optical spectra, it is necessary to account for electron-hole pair interactions, which is normally done by solving the Bethe-Salpeter equation (BSE) on top of GW calculations. ${ }^{46,82-85}$

By means of density functional theory and many-body methods with the inclusion of spin-orbit coupling, we have performed a systematic first-principles study of the structural, electronic, and optical properties of the $\mathrm{FAPb}\left(\mathrm{I}_{1-x} \mathrm{Br}_{x}\right)_{3}$ alloy with $0 \leq x \leq 1$. Our results show that as the $\mathrm{Br}$ concentration increases, the volume of the FAPb $\left(\mathrm{I}_{1-x} \mathrm{Br}_{x}\right)_{3}$ alloy decreases, the band gap increases from $1.47 \mathrm{eV}$ for pure $\alpha-\mathrm{FAPbI}_{3}$ to $2.20 \mathrm{eV}$ for Br-rich $\alpha-\mathrm{FAPbBr}_{3}$, and the excitonic peaks are blue shifted. Our results further reveal strong $\mathrm{Br}$ concentration dependence of the exciton binding energy (varies from 74 to $112 \mathrm{meV}$ ) and the carrier effective masses as well as the high frequency dielectric constants. Our findings open the way to fine-tune the carrier transport properties of the material by chemical substitution and provide important insights to improve short circuit currents and power conversion efficiencies in solar cell devices.

\section{Computational details}

The FAPb $\left(\mathrm{I}_{1-x} \mathrm{Br}_{x}\right)_{3}$ alloy was modelled based on the experimental geometry of $\alpha-\mathrm{FAPbI}_{3}$ at $298 \mathrm{~K}^{86}$ and $\alpha-\mathrm{FAPbBr}_{3}$ at $275 \mathrm{~K}{ }^{87}$ The position of the FA molecule for the present system was taken from the molecular dynamics simulations of Taylor et al. ${ }^{88}$ The modeling of the $\mathrm{FAPb}\left(\mathrm{I}_{1-x} \mathrm{Br}_{x}\right)_{3}$ alloy was carried out by compositional assembly of seven independent configurations i.e., for $x=0$, $0.17,0.33,0.50,0.67,0.83$ and 1 . The unit cell of $\mathrm{FAPbI}_{3}$ is expanded to a $1 \times 1 \times 2$ tetragonal supercell, where an appropriately random substitution of $\mathrm{I}$ atoms with $\mathrm{Br}$ atoms is performed to obtain the corresponding compositions. ${ }^{89-91}$ Our DFT calculations were performed using the Vienna ab initio simulation package (VASP) ${ }^{92,93}$ with projector augmented (PAW) pseudopotentials. ${ }^{94}$ For the exchange correlation functional, PBE was used. ${ }^{67,68}$ An energy cutoff of $600 \mathrm{eV}$ and $\Gamma$-centered $6 \times 6 \times 3$ $k$-point sampling of the Brillouin zone were adopted for all structures. The valence electron configurations that were included in the calculations are $5 \mathrm{~d}^{10} 6 \mathrm{~s}^{2} 6 \mathrm{p}^{2}$ for $\mathrm{Pb}, 5 \mathrm{~s}^{2} 5 \mathrm{p}^{5}$ for $\mathrm{I}, 4 \mathrm{~s}^{2} 4 \mathrm{p}^{5}$ for $\mathrm{Br}, 2 \mathrm{~s}^{2} 2 \mathrm{p}^{3}$ for $\mathrm{N}, 1 \mathrm{~s}^{1}$ for $\mathrm{H}$ and $2 \mathrm{~s}^{2} 2 \mathrm{p}^{2}$ for $\mathrm{C}$. All the structural parameters were relaxed with a convergence threshold of $10^{-6} \mathrm{eV}$ in the total energy and the stopping convergence criterion for the forces on each atom was set to be $0.01 \mathrm{eV} \AA^{-1}$. To account for the van der Waals dispersion interactions, we used the rev-vdW-DF2 functional of Hamada. ${ }^{95}$ Due to the presence of heavy elements, the relativistic SOC effect was included in calculating the electronic and optical properties.

For the accurate electronic structure, in particular the band gap, we carried out delicate one-shot $\mathrm{G}_{0} \mathrm{~W}_{0}$ calculations using $\Gamma$-centered $4 \times 4 \times 2 k$-point sampling with 2200 empty bands, a dielectric cutoff energy of $150 \mathrm{eV}$ and 128 points on the frequency grid. The electron-hole interactions were accounted for by solving the BSE for the polarizability. 16 occupied and unoccupied QP energies were employed in constructing the BSE Hamiltonian and the screened interactions $\mathrm{W}$ were from the preceding $\mathrm{G}_{0} \mathrm{~W}_{0}$ calculations. The broadening parameter used in evaluation of the polarizability was chosen to be $0.1 \mathrm{eV}$. For the detailed GW + BSE methodology that the VASP code follows, we refer the readers to ref. 96 .

It is known that to obtain converged optical spectra and exciton binding energies, many $k$ points are normally needed. ${ }^{46,82}$ However, for the relatively large systems studied here, this is already prohibitive for the $\mathrm{G}_{0} \mathrm{~W}_{0}$ calculations. To address this issue, we followed the strategy proposed in ref. 46, where the optical spectra and exciton binding energies were calculated by a simplified approximation of BSE [termed as model BSE (mBSE)]. In mBSE calculations, the $\mathrm{QP}$ energies from $\mathrm{G}_{0} \mathrm{~W}_{0}$ calculations are approximated by the PBE one-electron energies with a scissor operator on the unoccupied orbitals such that the PBE 
one-electron gap matches the $\mathrm{G}_{0} \mathrm{~W}_{0}$ calculated band gap. This turns out to be a good approximation for the systems studied here (see good agreement between $\mathrm{G}_{0} \mathrm{~W}_{0}+\mathrm{SOC}$ and PBE + SCISSOR + SOC band structures in Fig. 4). In addition, the expensive calculations of the dielectric function matrix from $\mathrm{G}_{0} \mathrm{~W}_{0}$ are approximated by a simple analytical model dielectric function within the diagonal element approximation: ${ }^{46,82,96,97}$

$$
\varepsilon^{-1}(|\mathbf{G}|)=1-\left(1-\varepsilon_{\infty}^{-1}\right) \mathrm{e}^{-|\mathbf{G}|^{2} / 4 \mu^{2}},
$$

where $\varepsilon_{\infty}, \mu$, and $\mathbf{G}$ are the ion-clamped (high-frequency) dielectric constant, range-separation parameter, and plane-wave vector, respectively. $\varepsilon_{\infty}$ is calculated from $\mathrm{G}_{0} \mathrm{~W}_{0}$ calculations and $\mu$ is obtained by fitting eqn (1) to the $G_{0} W_{0}$ calculated diagonal elements of the dielectric function matrix. The obtained $\varepsilon_{\infty}, \mu$ and scissor parameters used in the mBSE calculations for all the systems studied are compiled in Table 6. As shown in Fig. 9(a), PBE + SCISSOR + mBSE reproduces very well the optical spectra obtained from $\mathrm{G}_{0} \mathrm{~W}_{0}+$ BSE for $\mathrm{FAPbI}_{3}$ on the same $4 \times 4 \times 2 k$-point mesh, though the spectra are not $k$-point converged, validating the good performance of the PBE + SCISSOR + mBSE approach in accurately describing the optical spectra as well as exciton binding energies for the systems considered in the present work.

By performing PBE + SCISSOR + mBSE calculations, we are able to check the $k$-point convergence by adopting a dense $k$-point mesh up to $18 \times 18 \times 9$. Our test calculations indicate that the spectra and exciton binding energies are well converged on a $16 \times 16 \times 8$ $k$-point mesh with an accuracy of about $3 \mathrm{meV}$ in the exciton binding energies [see Fig. 9(b) and (c)]. Therefore, the $16 \times 16 \times 8$ $k$-point mesh was used for all mBSE calculations. The exciton binding energies were calculated by the energy difference between the $\mathrm{G}_{0} \mathrm{~W}_{0}$ band gap and the first bright mBSE eigenvalue. Furthermore, for comparison purposes, the exciton binding energies were also estimated by using the Wannier Mott model: ${ }^{98} E_{\mathrm{b}} \approx 13.6 m_{\mathrm{r}}{ }^{*} / \varepsilon_{\infty}{ }^{2}$, where $m_{\mathrm{r}}{ }^{*}$ is the reduced mass $\left(\frac{1}{m_{\mathrm{r}}{ }^{*}}=\frac{1}{m_{\mathrm{e}}}+\frac{1}{m_{\mathrm{h}}}\right)$.

\section{Results and discussion}

\section{A. Structural properties}

The possible synthesis of a halide mixed perovskite is confirmed through the effective Goldsmith tolerance factor $t_{\text {eff }}{ }^{99-102}$ The atomic-ratio weighted average of the two different anions is used as the estimated effective anion size $r_{\text {eff. For the }}$ $\operatorname{FAPb}\left(\mathrm{I}_{1-x} \mathrm{Br}_{x}\right)_{3}$ composition:

$$
\begin{aligned}
& r_{\text {eff }}=x r_{\mathrm{Br}}+(1-x) r_{\mathrm{I}}, \\
& t_{\mathrm{eff}}=\frac{r_{\mathrm{FA}}+r_{\mathrm{eff}}}{\sqrt{2}\left(r_{\mathrm{Pb}}+r_{\mathrm{eff}}\right)},
\end{aligned}
$$

where $r_{\mathrm{FA}}, r_{\mathrm{Pb}}, r_{\mathrm{I}}$ and $r_{\mathrm{Br}}$ are the Shanon ionic radii of $\mathrm{FA}(2.53 \AA)$, $\mathrm{Pb}(1.19 \AA)$, I $(2.20 \AA)$ and $\mathrm{Br}(1.96 \AA)$, respectively. ${ }^{100,101}$ The stability of $\mathrm{BX}_{6}$ octahedra can be predicted by the octahedral factor $\lambda$, which (for the present case) is the ratio of the size of the B-cation $r_{\mathrm{Pb}}$ and the effective halide size $r_{\text {eff: }}$

$$
\lambda=\frac{r_{\mathrm{Pb}}}{r_{\mathrm{eff}}}
$$

Generally, for $\mathrm{ABX}_{3}$ perovskite-like structures, the tolerance factor is in the range $0.80 \leq t \leq 1.06$ and the octahedral factor lies between 0.442 and $0.895 .^{99,102}$ The calculated effective tolerance factor for the $\mathrm{FAPb}\left(\mathrm{I}_{1-x} \mathrm{Br}_{x}\right)_{3}$ system ranges from 0.987 to 1.008, thus confirming the perovskite structure as summarized in Table 1 . The octahedral factor values also affirm the stable perovskite structure as they lie between 0.541 and 0.607 for the $\mathrm{FAPb}\left(\mathrm{I}_{1-x} \mathrm{Br}_{x}\right)_{3}$ composition.

Table 2 summarizes the calculated lattice parameters of the $\operatorname{FAPb}\left(\mathrm{I}_{1-x} \mathrm{Br}_{x}\right)_{3}$ system for $x=0,0.17,0.33,0.50,0.67,0.83$, and 1 . The calculated averaged ground state lattice parameters for FAPbI $_{3}(a=6.38 \AA)$ and $\operatorname{FAPbBr}_{3}(a=6.01 \AA)$ using the PBE functional are in good agreement with experimental data, i.e., $6.36 \AA$ and $5.99 \AA$ for $\mathrm{FAPbI}_{3}$ and $\mathrm{FAPbBr}_{3}$, respectively, ${ }^{29,39,103,104}$ and the relaxed structure of $\alpha-\mathrm{FAPbI}_{3}$ is shown in Fig. 1 . In the full relaxation of the structures, the deviation from tetragonal symmetry is caused by the steric effect of the $\mathrm{FA}^{+}$cation.

Fig. 2 shows the overall decrease in volume of the $1 \times 1 \times 2$ supercell from $520.9 \AA^{3}$ to $454.2 \AA^{3}$ as the $\mathrm{Br}$ content increases, which is consistent with the decreasing experimental lattice constants. $^{19,29}$ Also, the $\mathrm{Pb}-\mathrm{X}$ (where $\mathrm{X}=\mathrm{I}$ and $\mathrm{Br}$ ) bond length reduces from $3.26 \AA$ to $2.96 \AA$, which can be attributed to the smaller ionic radius of the $\mathrm{Br}$ atom, which influences the interplanar geometry. Moreover, the electronic charge distribution is much stronger around the $\mathrm{Br}$ atom due to its higher electronegativity value (2.96) as compared to I (2.66). Thus, the heavy $\mathrm{Pb}$ atom will interact strongly with the $\mathrm{Br}$ atom due to the high electronegativity difference, which leads to the reduction in the bond length. ${ }^{105}$

\section{B. Electronic structures and band gaps}

In order to give an insight on the electronic structure, different approaches have been carried out. Table 3 summarizes the

Table 2 Calculated lattice parameters for different $\mathrm{FAPb}\left(\mathrm{I}_{1-x} \mathrm{Br}_{x}\right)_{3} \mathrm{com}$ -

\begin{tabular}{|c|c|c|c|c|c|c|c|}
\hline Br fraction $x$ & 0 & 0.17 & 0.33 & 0.50 & 0.67 & 0.83 & 1 \\
\hline Goldsmith tolerance factor $t$ & 0.987 & 0.990 & 0.993 & 0.997 & 1.000 & 1.004 & 1.008 \\
\hline Octahedral factor $\lambda$ & 0.540 & 0.550 & 0.561 & 0.572 & 0.583 & 0.594 & 0.607 \\
\hline
\end{tabular}
positions using the PBE functional

\begin{tabular}{lllllll}
\hline Composition $x$ & $a(\AA)$ & $b(\AA)$ & $c(\AA)$ & $\alpha\left(^{\circ}\right)$ & $\beta\left(^{\circ}\right)$ & $\gamma\left({ }^{\circ}\right)$ \\
\hline 0 & 6.33 & 6.51 & 12.66 & 90.00 & 92.80 & 90.00 \\
0.17 & 6.31 & 6.50 & 12.32 & 90.00 & 93.05 & 90.00 \\
0.33 & 6.29 & 6.52 & 11.99 & 90.00 & 93.28 & 90.00 \\
0.50 & 6.30 & 6.37 & 12.00 & 90.00 & 93.34 & 90.00 \\
0.67 & 6.30 & 6.17 & 12.09 & 90.00 & 93.49 & 90.00 \\
0.83 & 6.01 & 6.17 & 12.27 & 90.00 & 94.51 & 90.00 \\
1 & 5.96 & 6.16 & 11.92 & 90.00 & 94.90 & 90.00
\end{tabular}

Table 1 Calculated Goldsmith tolerance factor and octahedral factor for different $\mathrm{Br}$ compositions in the $\left.\mathrm{FAPb}\left(\mathrm{I}_{1-x} \mathrm{Br}\right)_{x}\right)_{3}$ alloy 


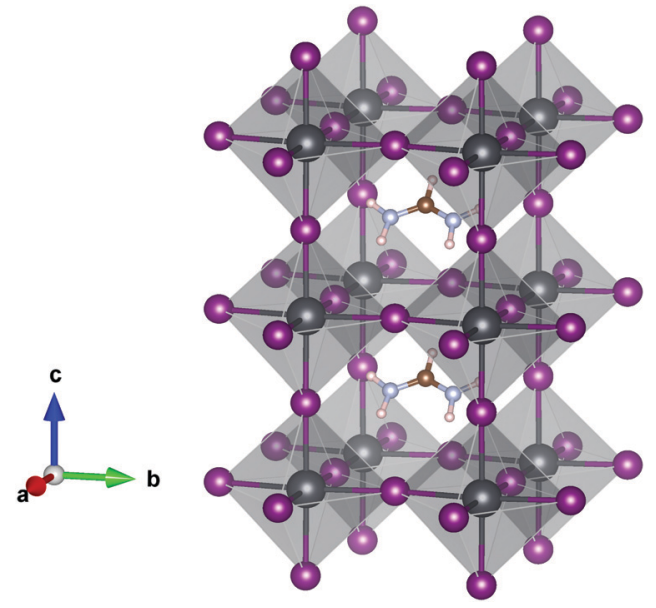

Fig. 1 Crystal structure of the $1 \times 1 \times 2$ supercell of $\alpha$-FAPbl 3 . Pb (grey), I (purple), $\mathrm{C}$ (brown), $\mathrm{N}$ (light blue) and $\mathrm{H}$ (pink). The $\mathrm{FAPb}\left(\mathrm{I}_{1-x} \mathrm{Br}_{x}\right)_{3}$ alloy is obtained by substituting I with $\mathrm{Br}$.

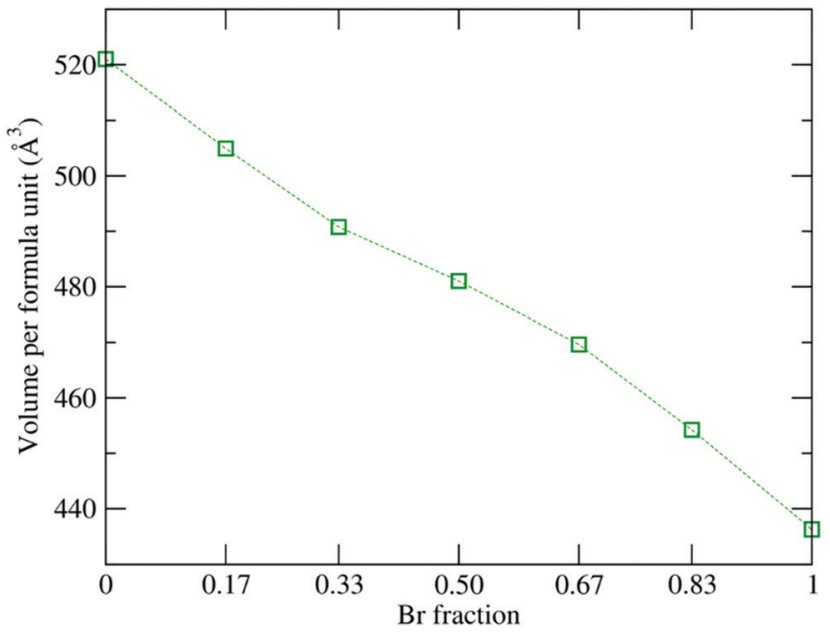

Fig. 2 Optimized volume as a function of $\mathrm{Br}$ concentration.

calculated band gaps for the $\mathrm{FAPb}\left(1_{1-x} \mathrm{Br}_{x}\right)_{3}$ system with increasing $\mathrm{Br}$ percentage obtained at various levels of theory. The comparison of the band gaps clearly shows the underestimation in the calculated band gaps of $\mathrm{FAPbI}_{3}$ and $\mathrm{FAPbBr}_{3}$ by $\mathrm{PBE}$, as expected. Inclusion of the relativistic SOC effect reduces the band gaps of $\mathrm{FAPbI}_{3}$ and $\mathrm{FAPbBr}_{3}$ to $0.41 \mathrm{eV}$ and $0.87 \mathrm{eV}$ respectively, underestimating the experimental band gap further and consistent with previous SOC-DFT results for $\operatorname{MA}(\mathrm{Pb}, \mathrm{Sn}) \mathrm{X}_{3}{ }^{46,71-77,81}$ To improve the underestimation in the PBE derived gaps, we carried out $\mathrm{G}_{0} \mathrm{~W}_{0}$ calculations including
SOC effects. The $\mathrm{G}_{0} \mathrm{~W}_{0}+\mathrm{SOC}$ calculated band gaps of $1.47 \mathrm{eV}$ and $2.20 \mathrm{eV}$ for $\mathrm{FAPbI}_{3}$ and $\mathrm{FAPbBr}_{3}$, respectively, are in excellent agreement with the experimental band gaps. ${ }^{19,29}$ Similarly, we have calculated the electronic band gaps using the $\mathrm{G}_{0} \mathrm{~W}_{0}+\mathrm{SOC}$ approach for all other configurations of $\mathrm{FAPb}\left(1_{1-x} \mathrm{Br}_{x}\right)_{3}$ having different $\mathrm{Br}$ compositions and the results are compiled in Table 3 .

The $\mathrm{G}_{0} \mathrm{~W}_{0}+$ SOC calculated band gaps for various $\mathrm{Br}$ fractions are plotted in Fig. 3. Such a linear trend in the band gaps with the $x$ composition in the alloy can be expressed by the quadratic equation known as Vegard's law: ${ }^{107,108}$

$$
\begin{aligned}
E_{\mathrm{g}}\left[\mathrm{FAPb}\left(\mathrm{Br}_{x} \mathrm{I}_{1-x}\right)_{3}\right]= & E_{\mathrm{g}}\left[\mathrm{FAPbI}_{3}\right]+\left(E_{\mathrm{g}}\left[\mathrm{FAPbBr}_{3}\right]\right. \\
& \left.-E_{\mathrm{g}}\left[\mathrm{FAPbI}_{3}\right]-b\right) x+b x^{2}
\end{aligned}
$$

where $b$ represents the bowing parameter and normally depends on the properties of the inter-substitutional atoms. ${ }^{107}$ The bowing parameter illustrates the level of fluctuation in the crystal field or the nonlinear effect arising from the anisotropic nature of binding. ${ }^{108}$ Eqn (5) yields the following expression:

$$
E_{\mathrm{g}}(x)=1.47+0.71 x+0.02 x^{2}
$$

which provides a good fit to the $\mathrm{G}_{0} \mathrm{~W}_{0}+$ SOC calculated band gaps as shown in Fig. 3, thus satisfying Vegard's law for the mixed $\mathrm{FAPb}\left(\mathrm{I}_{1-x} \mathrm{Br}_{x}\right)_{3}$ composition. The small bowing parameter $b=0.02$ shows that $\mathrm{FAPbI}_{3}$ and $\mathrm{FAPbBr}_{3}$ have excellent miscibility, yielding low compositional disorder for the mixed $\operatorname{FAPb}\left(\mathrm{I}_{1-x} \mathrm{Br}_{x}\right)_{3}$ system.

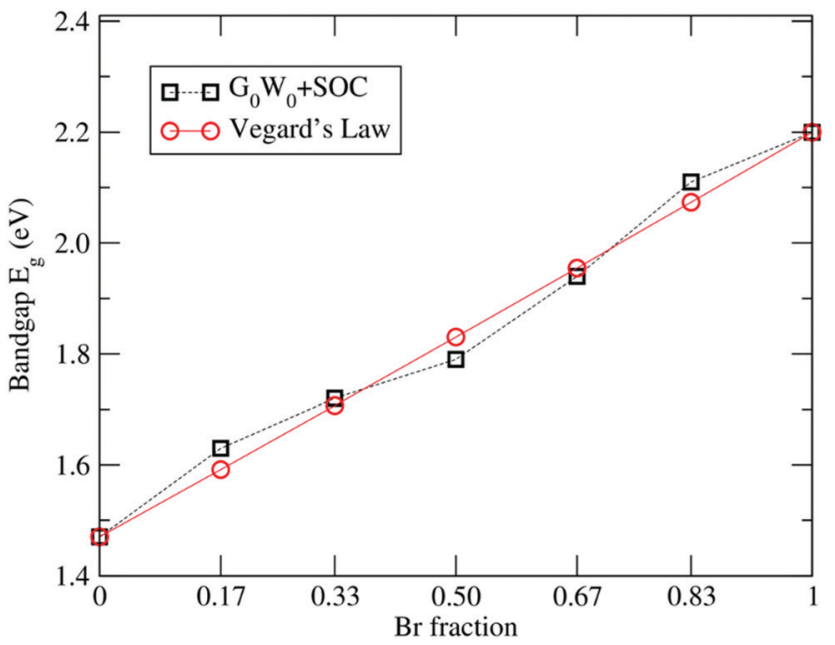

Fig. 3 Linear variation in the $\mathrm{G}_{0} \mathrm{~W}_{0}+\mathrm{SOC}$ calculated band gaps with respect to the $\mathrm{Br}$ concentration.

Table 3 Calculated bandgap values for different methods. The available experimental data are also shown for comparison

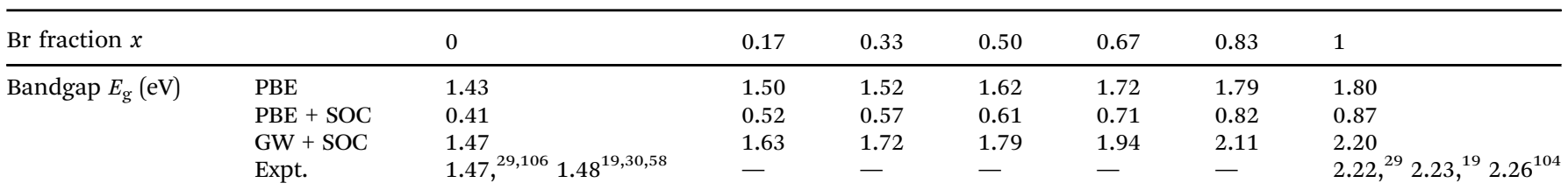




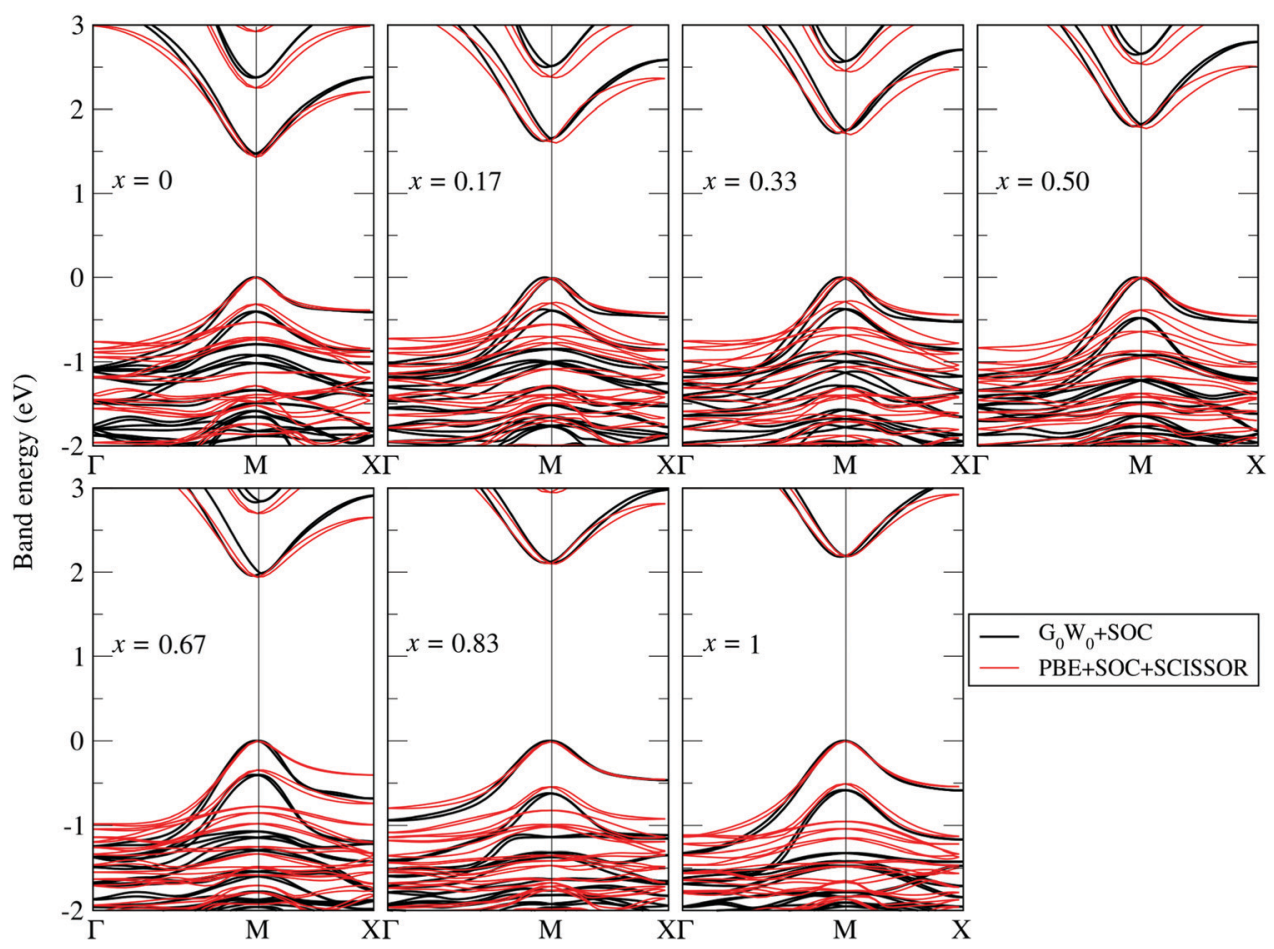

Fig. $4 \mathrm{G}_{0} \mathrm{~W}_{0}+\mathrm{SOC}$ calculated $\mathrm{QP}$ band structures obtained by Wannier interpolation ${ }^{109,110}$ (black lines) superposed by the PBE + SOC band structures with a scissor operator to match the $G_{0} W_{0}$ band gap (red lines). The Fermi level is set to zero.

The $\mathrm{G}_{0} \mathrm{~W}_{0}+$ SOC derived QP band structures along the highsymmetry points $\Gamma(0,0,0), M(0.5,0.5,0)$ and $X(0.5,0,0)$ for each $\operatorname{FAPb}\left(1_{1-x} \mathrm{Br}_{x}\right)_{3}$ configuration are shown in Fig. 4 . The band structures are plotted by using the Wannier interpolation scheme, ${ }^{109,110}$ in which the Wannier orbitals are constructed on a $\Gamma$-centered $4 \times 4 \times 2 k$-point mesh and all the relevant orbitals are included for the initial representation of the Kohn Sham states. With the $1 \times 1 \times 2$ supercell, both the valence band maximum (VBM) and conduction band minimum (CBM) fold to the $M$-point and the band gaps are found to be direct in nature. Fractional deviations from the $M$-point are observed for the VBM and CBM due to the presence of RashbaDresselhaus splitting. ${ }^{111-113}$ The dispersion of both the conduction band and valence band slightly increases with the $\mathrm{Br}$ content, leading to different effective masses for electrons and holes near the CBM and VBM. Such dispersions can be understood by the enhanced orbital interaction with decreasing structural volume.

To study the carrier transport properties for the $\mathrm{FAPb}\left(1_{1-x} \mathrm{Br}_{x}\right)_{3}$ alloy, we calculated the effective masses $m^{*}$ for electrons and holes around the CBM and VBM, respectively, by fitting the dispersion relation on the basis of the parabolic approximation

$$
m^{*}=\hbar^{2}\left[\frac{\partial^{2} E_{k}}{\partial k^{2}}\right]^{-1}
$$

where $E_{k}$ represents the QP electronic band energies and $k$ is the wave vector. Table 4 summarizes the effective masses of electrons $\left(m_{\mathrm{e}^{*}}\right)$ and holes $\left(m_{\mathrm{h}}{ }^{*}\right)$ for the investigated $\mathrm{FAPb}\left(1_{1-x} \mathrm{Br}_{x}\right)_{3}$
Table 4 Calculated effective masses for electrons and holes from the $\mathrm{G}_{0} \mathrm{~W}_{\mathrm{O}}+\mathrm{SOC}$ band structures

\begin{tabular}{|c|c|c|c|c|c|c|c|}
\hline \multirow{2}{*}{$\begin{array}{l}\mathrm{Br} \\
\text { fraction } x\end{array}$} & \multicolumn{2}{|c|}{$\begin{array}{l}\text { Effective } \\
\text { mass }(M-\Gamma)\end{array}$} & \multicolumn{2}{|c|}{$\begin{array}{l}\text { Effective } \\
\text { mass }(M-X)\end{array}$} & \multicolumn{2}{|l|}{ Average } & \multirow[b]{2}{*}{$m_{\mathrm{r}}^{*}$} \\
\hline & $m_{\mathrm{e}}^{*} / m_{0}$ & $m_{\mathrm{h}}^{*} / m_{0}$ & $m_{\mathrm{e}^{*} / m_{0}}$ & $m_{\mathrm{h}}^{*} / m_{0}$ & $m_{\mathrm{e}^{*} / m_{0}}$ & $m_{\mathrm{h}}{ }^{*} / m_{0}$ & \\
\hline 0 & 0.212 & 0.267 & 0.225 & 0.279 & 0.218 & 0.273 & 0.121 \\
\hline 0.17 & 0.227 & 0.288 & 0.234 & 0.298 & 0.231 & 0.293 & 0.129 \\
\hline 0.33 & 0.232 & 0.279 & 0.228 & 0.287 & 0.230 & 0.283 & 0.127 \\
\hline 0.50 & 0.253 & 0.296 & 0.255 & 0.304 & 0.254 & 0.300 & 0.138 \\
\hline 0.67 & 0.275 & 0.336 & 0.277 & 0.372 & 0.276 & 0.354 & 0.155 \\
\hline 0.83 & 0.369 & 0.467 & 0.364 & 0.431 & 0.367 & 0.449 & 0.202 \\
\hline 1 & 0.351 & 0.412 & 0.353 & 0.404 & 0.352 & 0.408 & 0.189 \\
\hline
\end{tabular}

compositions along the directions $M-\Gamma$ and $M-X$ and their averaged values. Further, the corresponding reduced masses $m_{\mathrm{r}}^{*}$ are also evaluated using the averaged values for $m_{\mathrm{e}}{ }^{*}$ and $m_{\mathrm{h}}{ }^{*}$. As can be seen in Fig. 5, the overall effective masses for electrons and holes increase with the $\mathrm{Br}$ fraction from $0.218 m_{0}$ to $0.352 m_{0}$ and $0.273 m_{0}$ to $0.408 m_{0}$, respectively. The slight deviation from linear behavior in the $m_{\mathrm{e}}{ }^{*}$ and $m_{\mathrm{h}}{ }^{*}$ values for $x=0.33$ and $x=0.83$ can be attributed to the high internal structural strain as compared to the other configurations. Since the carrier effective masses and mobility are inversely related, Fig. 5 clearly reveals that the mobility of the carriers varies with the $\mathrm{Br}$ content. For all considered configurations, $m_{\mathrm{h}}{ }^{*}$ is greater than $m_{\mathrm{e}}{ }^{*}$, so the mixed $\mathrm{FAPb}\left(1_{1-x} \mathrm{Br}_{x}\right)_{3}$ system can be regarded as a good electron transporter.

Fig. 6 depicts the $\mathrm{G}_{0} \mathrm{~W}_{0}+$ SOC calculated partial density of states (PDOS) to reveal the possible origin of the band gap variations. One can see that the electronic states near the band 


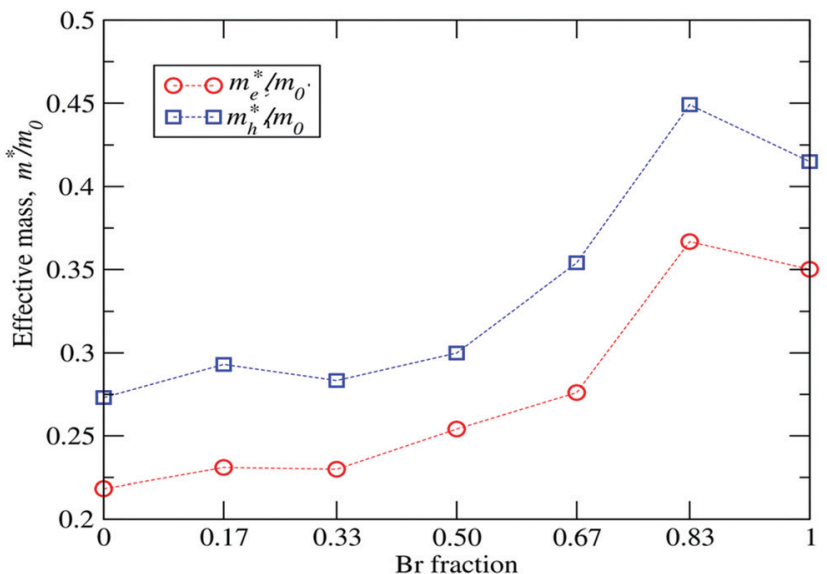

Fig. 5 Calculated $m_{\mathrm{e}}{ }^{*} / m_{0}$ and $m_{\mathrm{h}}{ }^{*} / m_{0}$ ratios as a function of the $\mathrm{Br}$ content, where $m_{\mathrm{e}}{ }^{\star}\left(m_{\mathrm{h}}{ }^{\star}\right)$ is the effective electron (hole) mass and $m_{0}$ is the mass of a free electron.

gap are mostly governed by the orbital overlap of the $\mathrm{BX}_{6}$ octahedron. The organic part does not contribute to the Fermi energy but acts as a charge compensating center, because the organic molecule weakly interacts with the inorganic part via possible hydrogen bonding through the organic cation groups. Thus, for the sake of clarity, around the band gap only the contributions from the orbitals ( $\mathrm{s}$ and $\mathrm{p}$ ) of $\mathrm{Pb}$, I and $\mathrm{Br}$ atoms are presented and analyzed. From the PDOS, the valence band is mainly composed of X-p orbitals, mixed in minor fractions with B-s orbitals, while the conduction band is mainly contributed by B-p orbitals, partly hybridized with X-s states. The gradual replacement of I with $\mathrm{Br}$ causes the $\mathrm{Br}-4 \mathrm{p}$ orbital to dominate at the VBM, which tends to strongly hybridize with $\mathrm{Pb}-\mathrm{s}$ states as compared to I-p states. This pushes the CBM towards the high energy region and thus increases the band gap. Such orbital behavior has also been observed in a DFT study of the $\operatorname{MAPb}\left(1_{1-x} \mathrm{Br}_{x}\right)_{3}$ system. $^{57}$

\section{Optical properties and exciton binding energies}

To explore the excitonic behavior for each $\operatorname{FAPb}\left(1_{1-x} \mathrm{Br}_{x}\right)_{3}$ configuration, we carried out PBE + SCISSOR + mBSE calculations including the SOC effect. An exciton is a neutral bound electron-hole pair, which plays a crucial role in the optical excitation process and is highly influential for both fundamental science and applications in solar cells. ${ }^{45-52}$ Therefore, it is essential to consider the electron-hole Coulomb interactions for an accurate excitonic description of the optical spectra.

Previously, it has been revealed that the polaronic effects in HOIPs contribute to excitonic features due to the interacting longitudinal optical phonons with electronic states of the carriers, thereby forming polarons, which influences the dielectric behavior and exciton binding energies. ${ }^{38,46,48,114}$ However, polaronic effects are not considered here, since they are beyond the scope of this work. Fig. 7 shows the imaginary part of the dielectric function $\operatorname{Im}[\varepsilon(\omega)]$ with increasing $\mathrm{Br}$ composition along with the corresponding optical transition oscillator strengths. One can see that $\operatorname{Im}[\varepsilon(\omega)]$ for all compositions shows a typical three peak feature in the considered energy range: two peaks are above the $\mathrm{G}_{0} \mathrm{~W}_{0}$ band gap and one peak is below the $\mathrm{G}_{0} \mathrm{~W}_{0}$ band gap, which is an exciton peak resulting from the electron-hole interactions upon photoexcitation. Our PBE + SCISSOR + mBSE calculated spectra for $x=0, x=0.67$, and $x=1$ are in good agreement with available experimentally measured data, ${ }^{115-118}$ in particular the first two peaks. The spectrum of $x=0$ from M. Kato et al. ${ }^{116}$ is largely blue-shifted for the first

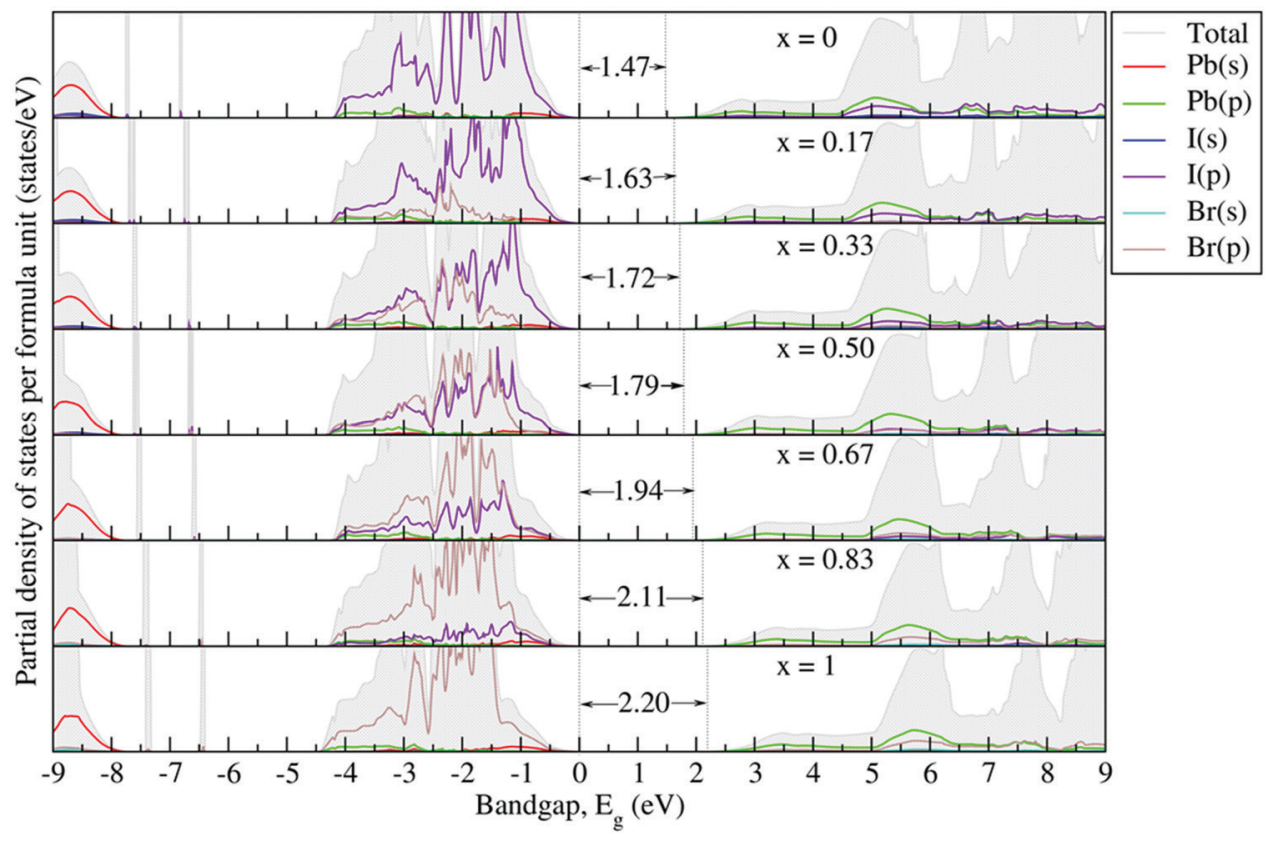

Fig. $6 \mathrm{G}_{0} \mathrm{~W}_{0}+\mathrm{SOC}$ calculated partial density of states for the $\mathrm{FAPb}\left(\left.\right|_{1-x} \mathrm{Br}_{x}\right)_{3}$ system. The Fermi level is set to zero. 


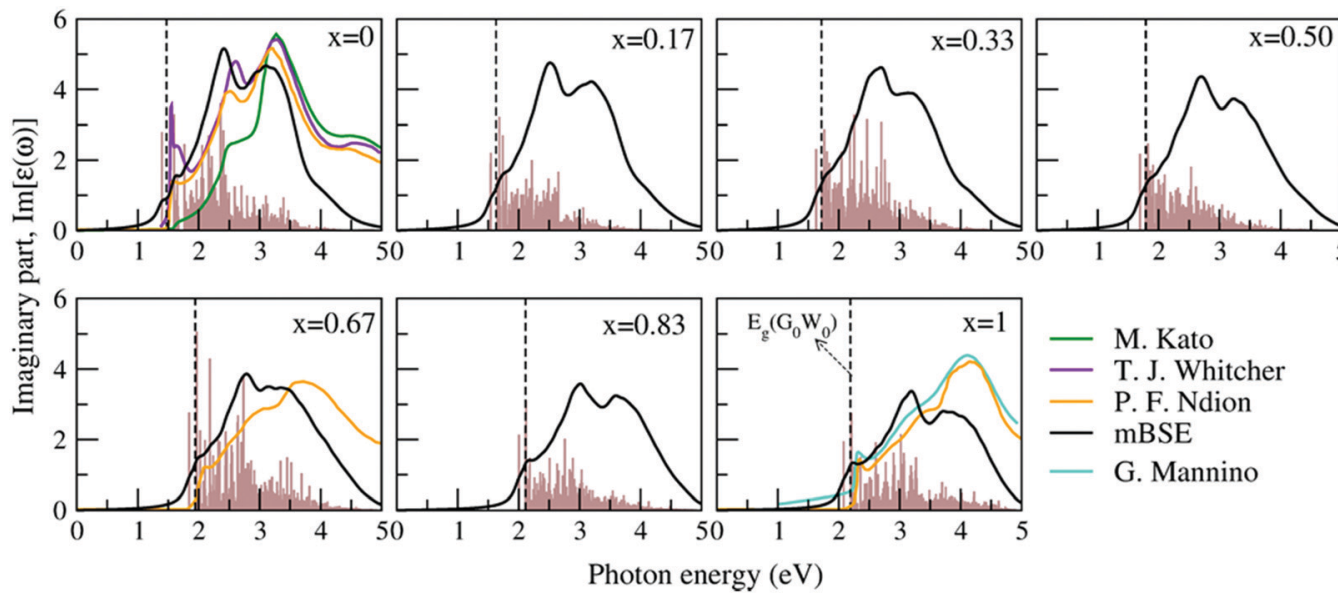

Fig. $7 \mathrm{PBE}+\mathrm{SCISSOR}+\mathrm{mBSE}$ calculated imaginary part $\operatorname{Im}[\varepsilon(\omega)]$ of the dielectric function of the $\mathrm{FAPb}\left(\mathrm{I}_{1-x} \mathrm{Br}_{x}\right)_{3}$ alloy. The corresponding $\mathrm{G}_{0} \mathrm{~W}_{0}$ derived fundamental gap $E_{\mathrm{g}}\left(\mathrm{G}_{0} \mathrm{~W}_{0}\right)$ and optical transition oscillator strengths are represented by dashed lines and brown histograms, respectively. The available experimental data on $\mathrm{FAPbl}_{3}{ }_{1}^{115-117} \mathrm{FAPbIBr}_{2}{ }^{117}$ and $\mathrm{FAPbBr}_{3}{ }^{118}$ are shown for comparison. Note that the $\operatorname{Im}[\varepsilon(\omega)]$ data shown here from ref. 117 are indirectly calculated from the experimentally measured refractive index and extinction coefficient.

Table 5 Calculated high frequency dielectric constant $\varepsilon_{\infty}$ and exciton binding energies $E_{\mathrm{b}}(\mathrm{meV})$ from both the Wannier Mott model and mBSE

\begin{tabular}{lcccccc}
\hline Br fraction $x$ & 0 & 0.17 & 0.33 & 0.50 & 0.67 & 0.83 \\
\hline High frequency dielectric constant $\varepsilon_{\infty}$ & 5.320 & 4.929 & 4.746 & 4.613 & 4.447 & 4.266 \\
$E_{\mathrm{b}}$ (Wannier Mott model) & 58 & 72 & 77 & 88 & 4.173 \\
$E_{\mathrm{b}}$ (mBSE) & 74 & 85 & 90 & 95 & 99 & 151 \\
\hline
\end{tabular}

two peaks as compared to that of T. J. Whitcher et al. ${ }^{115}$ and P. F. Ndion et al. ${ }^{117}$ as well as our simulated one. As the $\mathrm{Br}$ fraction increases from $x=0$ to $x=1$, the optical spectra are systematically blue-shifted along with the gradual reduction in the overall amplitude of oscillator strengths. This trend is consistent with the increasing band gaps and can be attributed to variation in the electronic charge distribution of X-p states with changing halide component as evident from the PDOS of Fig. 6 .

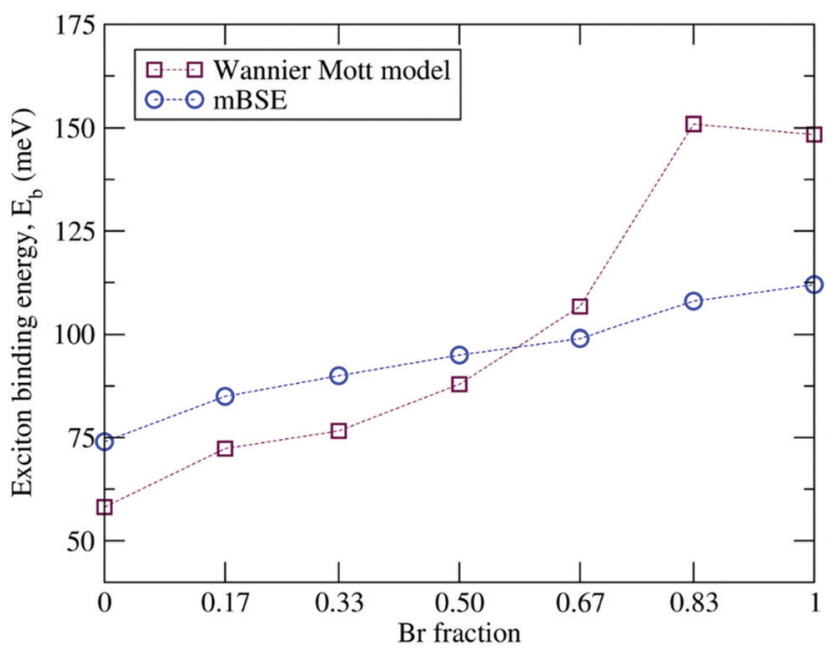

Fig. 8 Calculated exciton binding energies as a function of the $\mathrm{Br}$ fraction.
Since changes in the halide components affect the bound state of an electron-hole pair, we evaluated the exciton binding energies $E_{\mathrm{b}}$ within Wannier-Mott theory by using the effective mass approximation as well as via mBSE. The resulting exciton binding energies are summarized in Table 5 and depicted in Fig. 8. One can observe that the mBSE calculated exciton binding energies almost show linear behavior as the Br concentration increases and this trend is in general captured by Wannier-Mott theory, though the values deviate. The mBSE calculated $E_{\mathrm{b}}$ for $\alpha-\mathrm{FAPbI}_{3}(74 \mathrm{meV})$ is significantly large as compared to the experimental value of $2.4 \mathrm{meV},{ }^{119}$ whereas for the pure $\alpha-\mathrm{FAPbBr}_{3}$ the calculated $E_{\mathrm{b}}(112 \mathrm{meV})$ is in reasonable agreement with the experimental value of $170 \mathrm{meV} .{ }^{103}$ For the latter, Wannier-Mott theory yields a better value of $E_{\mathrm{b}}$ towards the experimental value. From Wannier-Mott theory, we can infer that the overall increase in $E_{\mathrm{b}}$ with increasing $\mathrm{Br}$ concentration in $\mathrm{FAPb}\left(\mathrm{I}_{1-x} \mathrm{Br}_{x}\right)_{3}$ is both affected by increasing $m_{\mathrm{r}}{ }^{*}$ and decreasing $\varepsilon_{\infty}$. The smaller value of $E_{\mathrm{b}}$ in the I-rich configuration requires smaller energy to dissociate the electron-hole pair, which in turn leads to high optical absorption and high PCE as compared to the Br-rich material.

\section{Conclusions}

We have performed a first-principles study of the structural, electronic, and optical properties of the $\mathrm{FAPb}\left(\mathrm{I}_{1-x} \mathrm{Br}_{x}\right)_{3}$ alloy $0 \leq x \leq 1$ by means of density functional theory and manybody methods with the inclusion of spin-orbit coupling. The calculated geometrical parameters show that the overall $\mathrm{Pb}-\mathrm{X}$ 
bond length decreases with the $\mathrm{Br}$ content and thus reduces the volume, which is in agreement with experiments. The $\mathrm{G}_{0} \mathrm{~W}_{0}$ derived band gap increases from $1.47 \mathrm{eV}$ to $2.20 \mathrm{eV}$ with increasing $\mathrm{Br}$ fraction, which has been clearly demonstrated from the evolution of the electronic density of states. The $\mathrm{G}_{0} \mathrm{~W}_{0}+\mathrm{BSE}$ calculated optical spectra show that the overall excitonic peaks are blue shifted with increasing $\mathrm{Br}$ concentration, which shows a strong correlation with the increase in the band gap and is consistent with the decreasing dielectric constants. The variation in the exciton binding energy from $74 \mathrm{meV}$ to $112 \mathrm{meV}$ reveals that excitons are more bound for $\mathrm{Br}$ rich compounds due to the reduced carrier mobility and thus require a higher energy for exciton dissociation. Our findings provide an efficient and controllable way to tune the electronic as well as the optical properties for mixed HOIPs that will be beneficial for material design of high performance tandem solar cells.

\section{Conflicts of interest}

There are no conflicts to declare.

\section{Appendix A}

In this appendix, we show in Table 6 the required parameters used for PBE + SCISSOR + mBSE calculations and in Fig. 9 we take $\mathrm{FAPbI}_{3}$ as an example to illustrate how mBSE performs as compared to the full BSE and how the calculated optical spectra as well as exciton binding energies converge with respect to the number of $k$ points.

Fig. 9(a) shows a comparison of the imaginary part of the dielectric function calculated from $\mathrm{G}_{0} \mathrm{~W}_{0}+\mathrm{BSE}$ and $\mathrm{PBE}+$ SCISSOR + mBSE on a $4 \times 4 \times 2 k$-point mesh. One can see that PBE + SCISSOR + mBSE in general reproduces very well the spectra obtained from $\mathrm{G}_{0} \mathrm{~W}_{0}+\mathrm{BSE}$, in particular the first bright peak, suggesting that PBE + SCISSOR + mBSE is a suitable method to describe the optical spectra for $\mathrm{FAPbI}_{3}$ with an accuracy that is comparable with the more demanding $\mathrm{G}_{0} \mathrm{~W}_{0}+\mathrm{BSE}$.

Fig. 9(b) and (c) display the convergence of the optical spectra and exciton biding energies calculated from PBE + SCISSOR + mBSE with respect to the number of $k$ points. Clearly and expectedly, the convergence is very slow. Our calculations indicate that the spectra and exciton binding energies are converged with a $16 \times 16 \times 8 k$-point mesh, with an accuracy of about $3 \mathrm{meV}$ in the exciton binding energies.

Table 6 The parameters used for PBE + SCISSOR + mBSE calculations

\begin{tabular}{llllllll}
\hline Br fraction $x$ & 0 & 0.17 & 0.33 & 0.50 & 0.67 & 0.83 & 1 \\
\hline$\varepsilon_{\infty}\left(\AA^{-1}\right)$ & 5.320 & 4.929 & 4.746 & 4.613 & 4.447 & 4.266 & 4.173 \\
$\mu$ & 1.055 & 1.060 & 1.070 & 1.073 & 1.081 & 1.095 & 1.109 \\
SCISSOR (eV) & 1.062 & 1.095 & 1.133 & 1.171 & 1.233 & 1.283 & 1.319
\end{tabular}
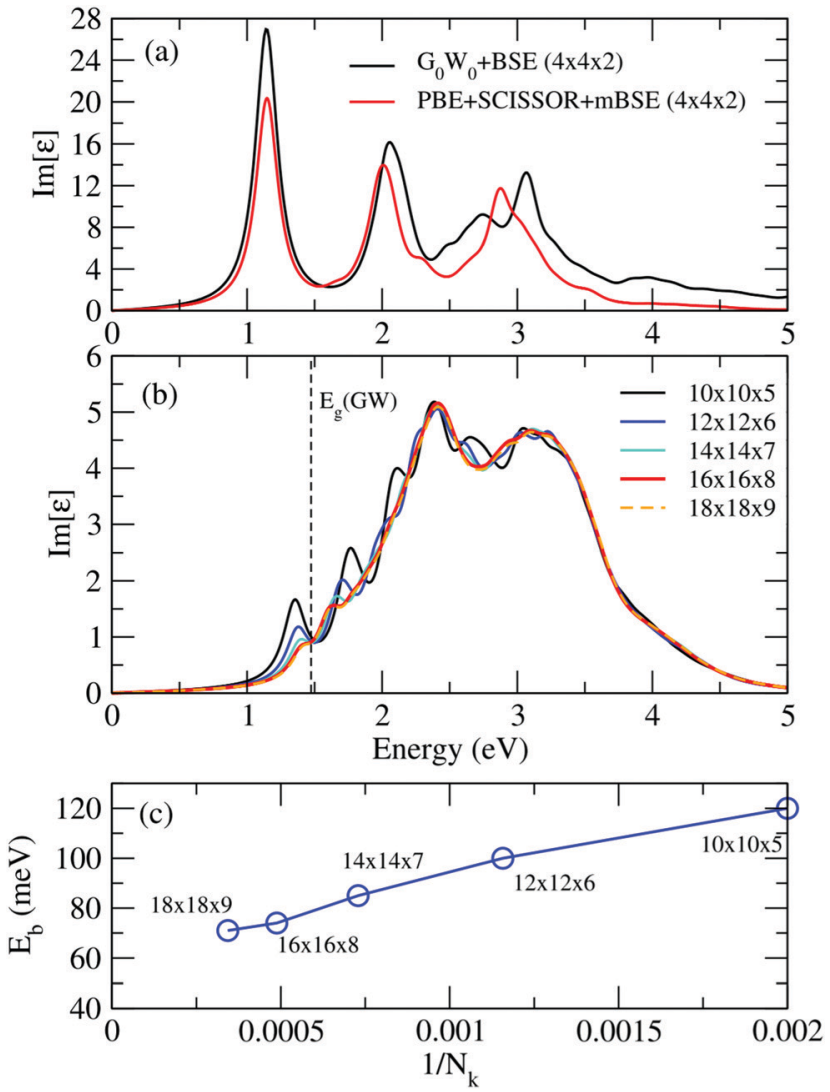

Fig. 9 (a) Comparison of the imaginary part of the dielectric function calculated from $G_{0} W_{0}+$ BSE (black lines) and PBE + SCISSOR + mBSE (red lines) on a $4 \times 4 \times 2 k$-point mesh. Convergence of the (b) spectra and (c) exciton biding energies calculated from PBE + SCISSOR + mBSE with respect to the number of $k$ points. All calculations here are performed on $\mathrm{FAPbl}_{3}$.

\section{Acknowledgements}

Z. Muhammad is thankful to M. Reticcioli for helpful discussions. This work was supported by the Higher Education Commission of Pakistan (HEC) under the Research Project No. 20-3959/NRPU/R\&D/HEC2014/234. P. Liu and C. Franchini acknowledge support from the Austrian Science Fund (FWF). The Vienna Scientific cluster (VSC) is gratefully acknowledged for computing facilities.

\section{References}

1 A. Kojima, K. Teshima, Y. Shirai and T. Miyasaka, Organometal Halide Perovskites as Visible-Light Sensitizers for Photovoltaic Cells, J. Am. Chem. Soc., 2009, 131, 6050-6051.

2 J.-H. Im, C.-R. Lee, J.-W. Lee, S.-W. Park and N.-G. Park, $6.5 \%$ efficient perovskite quantum-dot-sensitized solar cell, Nanoscale, 2011, 3, 4088.

3 H.-S. Kim, C.-R. Lee, J.-H. Im, K.-B. Lee, T. Moehl, A. Marchioro, S.-J. Moon, R. Humphry-Baker, J.-H. Yum, J. E. Moser, M. Grätzel and N.-G. Park, Lead Iodide Perovskite Sensitized All-Solid-State Submicron Thin Film 
Mesoscopic Solar Cell with Efficiency Exceeding 9\%, Sci. Rep., 2012, 2, 591.

4 M. M. Lee, J. Teuscher, T. Miyasaka, T. N. Murakami and H. J. Snaith, Efficient hybrid solar cells based on mesosuperstructured organometal halide perovskites, Science, 2012, 338, 643-647.

5 J. H. Noh, S. H. Im, J. H. Heo, T. N. Mandal and S. Il Seok, Chemical management for colorful, efficient, and stable inorganic-organic hybrid nanostructured solar cells, Nano Lett., 2013, 13, 1764-1769.

6 M. Liu, M. B. Johnston and H. J. Snaith, Efficient planar heterojunction perovskite solar cells by vapour deposition, Nature, 2013, 501, 395-398.

7 J. M. Ball, M. M. Lee, A. Hey and H. J. Snaith, Lowtemperature processed meso-superstructured to thin-film perovskite solar cells, Energy Environ. Sci., 2013, 6, 1739.

8 J. Burschka, N. Pellet, S.-J. Moon, R. Humphry-Baker, P. Gao, M. K. Nazeeruddin and M. Grätzel, Sequential deposition as a route to high-performance perovskitesensitized solar cells, Nature, 2013, 499, 316-319.

9 Q. Chen, H. Zhou, Z. Hong, S. Luo, H.-S. Duan, H.-H. Wang, Y. Liu, G. Li and Y. Yang, Planar Heterojunction Perovskite Solar Cells via Vapor-Assisted Solution Process, J. Am. Chem. Soc., 2014, 136, 622-625.

10 D. Liu and T. L. Kelly, Perovskite solar cells with a planar heterojunction structure prepared using room-temperature solution processing techniques, Nat. Photonics, 2014, 8, 133-138.

11 H. Zhou, Q. Chen, G. Li, S. Luo, T. Song, H.-S. Duan, Z. Hong, J. You, Y. Liu and Y. Yang, Photovoltaics. Interface engineering of highly efficient perovskite solar cells, Science, 2014, 345, 542-546.

12 W. S. Yang, J. H. Noh, N. J. Jeon, Y. C. Kim, S. Ryu, J. Seo and S. Il Seok, SOLAR CELLS. High-performance photovoltaic perovskite layers fabricated through intramolecular exchange, Science, 2015, 348, 1234-1237.

13 M. Saliba, T. Matsui, J.-Y. Seo, K. Domanski, J.-P. CorreaBaena, M. K. Nazeeruddin, S. M. Zakeeruddin, W. Tress, A. Abate, A. Hagfeldt and M. Grätzel, Cesium-containing triple cation perovskite solar cells: improved stability, reproducibility and high efficiency, Energy Environ. Sci., 2016, 9, 1989-1997.

14 W. S. Yang, B.-W. Park, E. H. Jung, N. J. Jeon, Y. C. Kim, D. U. Lee, S. S. Shin, J. Seo, E. K. Kim, J. H. Noh and S. Il Seok, Iodide management in formamidinium-lead-halidebased perovskite layers for efficient solar cells, Science, 2017, 356, 1376-1379.

15 K. A. Bush, A. F. Palmstrom, Z. J. Yu, M. Boccard, R. Cheacharoen, J. P. Mailoa, D. P. McMeekin, R. L. Z. Hoye, C. D. Bailie, T. Leijtens, I. M. Peters, M. C. Minichetti, N. Rolston, R. Prasanna, S. Sofia, D. Harwood, W. Ma, F. Moghadam, H. J. Snaith, T. Buonassisi, Z. C. Holman, S. F. Bent and M. D. McGehee, 23.6\%-efficient monolithic perovskite/silicon tandem solar cells with improved stability, Nat. Energy, 2017, 2, 17009.

16 F. Sahli, J. Werner, B. A. Kamino, M. Bräuninger, R. Monnard, B. Paviet-Salomon, L. Barraud, L. Ding, J. J. Diaz Leon,
D. Sacchetto, G. Cattaneo, M. Despeisse, M. Boccard, S. Nicolay, Q. Jeangros, B. Niesen and C. Ballif, Fully textured monolithic perovskite/silicon tandem solar cells with $25.2 \%$ power conversion efficiency, Nat. Mater., 2018, 17, 820-826.

17 S. Gharibzadeh, I. M. Hossain, P. Fassl, B. A. Nejand, T. Abzieher, M. Schultes, E. Ahlswede, P. Jackson, M. Powalla, S. Schäfer, M. Rienäcker, T. Wietler, R. Peibst, U. Lemmer, B. S. Richards and U. W. Paetzold, 2D/3D Heterostructure for Semitransparent Perovskite Solar Cells with Engineered Bandgap Enables Efficiencies Exceeding $25 \%$ in Four-Terminal Tandems with Silicon and CIGS, Adv. Funct. Mater., 2020, 1909919.

18 S. Colella, E. Mosconi, P. Fedeli, A. Listorti, F. Gazza, F. Orlandi, P. Ferro, T. Besagni, A. Rizzo, G. Calestani, G. Gigli, F. De Angelis and R. Mosca, $\mathrm{MAPbI}_{3-x} \mathrm{Cl}_{x}$ mixed halide perovskite for hybrid solar cells: The role of chloride as dopant on the transport and structural properties, Chem. Mater., 2013, 25, 4613-4618.

19 G. E. Eperon, S. D. Stranks, C. Menelaou, M. B. Johnston, L. M. Herz and H. J. Snaith, Formamidinium lead trihalide: A broadly tunable perovskite for efficient planar heterojunction solar cells, Energy Environ. Sci., 2014, 7, 982-988.

20 F. Hao, C. C. Stoumpos, R. P. H. Chang and M. G. Kanatzidis, Anomalous Band Gap Behavior in Mixed Sn and $\mathrm{Pb}$ Perovskites Enables Broadening of Absorption Spectrum in Solar Cells, J. Am. Chem. Soc., 2014, 136, 8094-8099.

21 Y. Ogomi, A. Morita, S. Tsukamoto, T. Saitho, N. Fujikawa, Q. Shen, T. Toyoda, K. Yoshino, S. S. Pandey, T. Ma and S. Hayase, $\mathrm{CH}_{3} \mathrm{NH}_{3} \mathrm{Sn}_{x} \mathrm{~Pb}_{(1-x)} \mathrm{I}_{3}$ perovskite solar cells covering up to $1060 \mathrm{~nm}$, J. Phys. Chem. Lett., 2014, 5, 1004-1011.

22 W. Rehman, R. L. Milot, G. E. Eperon, C. Wehrenfennig, J. L. Boland, H. J. Snaith, M. B. Johnston and L. M. Herz, Charge-Carrier Dynamics and Mobilities in Formamidinium Lead Mixed-Halide Perovskites, Adv. Mater., 2015, 27, 7938-7944.

23 B. Slimi, M. Mollar, I. Ben Assaker, I. Kriaa, R. Chtourou and B. Marí, Perovskite $\mathrm{FA}_{1-x} \mathrm{MA}_{x} \mathrm{PbI}_{3}$ for Solar Cells: Films Formation and Properties, Energy Procedia, 2016, 102, 87-95.

24 D. Bi, W. Tress, M. I. Dar, P. Gao, J. Luo, C. Renevier, K. Schenk, A. Abate, F. Giordano, J. P. Correa Baena, J. D. Decoppet, S. M. Zakeeruddin, M. K. Nazeeruddin, M. Grätzel and A. Hagfeldt, Efficient luminescent solar cells based on tailored mixed-cation perovskites, Sci. Adv., 2016, 2, e1501170.

25 F. Xu, T. Zhang, G. Li and Y. Zhao, Mixed cation hybrid lead halide perovskites with enhanced performance and stability, J. Mater. Chem. A, 2017, 5, 11450-11461.

26 D. J. Kubicki, D. Prochowicz, A. Hofstetter, P. Péchy, S. M. Zakeeruddin, M. Grätzel and L. Emsley, Cation Dynamics in Mixed-Cation $(\mathrm{MA})_{x}(\mathrm{FA})_{1-x} \mathrm{PbI}_{3}$ Hybrid Perovskites from Solid-State NMR, J. Am. Chem. Soc., 2017, 139, 10055-10061. 
27 L. Li, N. Liu, Z. Xu, Q. Chen, X. Wang and H. Zhou, Precise Composition Tailoring of Mixed-Cation Hybrid Perovskites for Efficient Solar Cells by Mixture Design Methods, ACS Nano, 2017, 11, 8804-8813.

28 B. Zhang, F. Guo, J. Xue, L. Yang, Y. Zhao, M. Ge, Q. Cai, B. Liu, Z. Xie, D. Chen, H. Lu, R. Zhang and Y. Zheng, Photoluminescence Study of the Photoinduced Phase Separation in Mixed-Halide Hybrid Perovskite $\mathrm{CH}_{3} \mathrm{NH}_{3} \mathrm{~Pb}$ $\left(\mathrm{Br}_{x} \mathrm{I}_{1-x}\right)_{3}$ Crystals Synthesized via a Solvothermal Method, Sci. Rep., 2017, 7, 17695.

29 B. Slimi, M. Mollar, I. Ben Assaker, A. Kriaa, R. Chtourou and B. Marí, Synthesis and characterization of perovskite $\mathrm{FAPbBr}_{3-x} \mathrm{I}_{x}$ thin films for solar cells, Monatsh. Chem., 2017, 148, 835-844.

30 A. Pisanu, C. Ferrara, P. Quadrelli, G. Guizzetti, M. Patrini, C. Milanese, C. Tealdi and L. Malavasi, The $\mathrm{FA}_{1-x} \mathrm{MA}_{x} \mathrm{PbI}_{3}$ System: Correlations among Stoichiometry Control, Crystal Structure, Optical Properties, and Phase Stability, J. Phys. Chem. C, 2017, 121, 8746-8751.

31 K. A. Bush, K. Frohna, R. Prasanna, R. E. Beal, T. Leijtens, S. A. Swifter and M. D. McGehee, Compositional Engineering for Efficient Wide Band Gap Perovskites with Improved Stability to Photoinduced Phase Segregation, ACS Energy Lett., 2018, 3, 428-435.

32 E. S. Parrott, T. Green, R. L. Milot, M. B. Johnston, H. J. Snaith and L. M. Herz, Interplay of Structural and Optoelectronic Properties in Formamidinium Mixed Tin-Lead Triiodide Perovskites, Adv. Funct. Mater., 2018, 28, 1802803.

33 A. Pisanu, A. Mahata, E. Mosconi, M. Patrini, P. Quadrelli, C. Milanese, F. De Angelis and L. Malavasi, Exploring the Limits of Three-Dimensional Perovskites: The Case of $\mathrm{FAPb}_{1-x} \mathrm{Sn}_{x} \mathrm{Br}_{3}$, ACS Energy Lett., 2018, 3, 1353-1359.

34 A. Leblanc, N. Mercier, M. Allain, J. Dittmer, T. Pauporté, V. Fernandez, F. Boucher, M. Kepenekian and C. Katan, Enhanced Stability and Band Gap Tuning of $\alpha-\left[\mathrm{HC}\left(\mathrm{NH}_{2}\right)_{2}\right]$ $\mathrm{PbI}_{3}$ Hybrid Perovskite by Large Cation Integration, ACS Appl. Mater. Interfaces, 2019, 11, 20743-20751.

35 T. Jiang, Z. Chen, X. Chen, X. Chen, X. Xu, T. Liu, L. Bai, D. Yang, D. Di, W. E. I. Sha, H. Zhu and Y. M. Yang, Power Conversion Efficiency Enhancement of Low-Bandgap Mixed Pb-Sn Perovskite Solar Cells by Improved Interfacial Charge Transfer, ACS Energy Lett., 2019, 4, 1784-1790.

36 F. Lehmann, A. Franz, D. M. Többens, S. Levcenco, T. Unold, A. Taubert and S. Schorr, The phase diagram of a mixed halide ( $\mathrm{Br}, \mathrm{I})$ hybrid perovskite obtained by synchrotron X-ray diffraction, $R S C A d v$., 2019, 9, 11151-11159.

37 W. Fan, Y. Shi, T. Shi, S. Chu, W. Chen, K. O. Ighodalo, J. Zhao, X. Li and Z. Xiao, Suppression and Reversion of Light-Induced Phase Separation in Mixed-Halide Perovskites by Oxygen Passivation, ACS Energy Lett., 2019, 4, 2052-2058.

38 Y. Chen, H. T. Yi, X. Wu, R. Haroldson, Y. N. Gartstein, Y. I. Rodionov, K. S. Tikhonov, A. Zakhidov, X. Y. Zhu and V. Podzorov, Extended carrier lifetimes and diffusion in hybrid perovskites revealed by Hall effect and photoconductivity measurements, Nat. Commun., 2016, 7, 12253.

39 A. A. Zhumekenov, M. I. Saidaminov, M. A. Haque, E. Alarousu, S. P. Sarmah, B. Murali, I. Dursun, X.-H. Miao, A. L. Abdelhady, T. Wu, O. F. Mohammed and O. M. Bakr, Formamidinium Lead Halide Perovskite Crystals with Unprecedented Long Carrier Dynamics and Diffusion Length, ACS Energy Lett., 2016, 1, 32-37.

40 G. Xing, N. Mathews, S. Sun, S. S. Lim, Y. M. Lam, M. Grätzel, S. Mhaisalkar and T. C. Sum, Long-range balanced electron- and hole-transport lengths in organicinorganic $\mathrm{CH}_{3} \mathrm{NH}_{3} \mathrm{PbI}_{3}$, Science, 2013, 342, 344-347.

41 C. Wehrenfennig, G. E. Eperon, M. B. Johnston, H. J. Snaith and L. M. Herz, High charge carrier mobilities and lifetimes in organolead trihalide perovskites, $A d v$. Mater., 2014, 26, 1584-1589.

42 J. Lim, M. T. Hörantner, N. Sakai, J. M. Ball, S. Mahesh, N. K. Noel, Y. H. Lin, J. B. Patel, D. P. McMeekin, M. B. Johnston, B. Wenger and H. J. Snaith, Elucidating the longrange charge carrier mobility in metal halide perovskite thin films, Energy Environ. Sci., 2019, 12, 169-176.

43 N. T. P. Hartono, S. Sun, M. C. Gélvez-Rueda, P. J. Pierone, M. P. Erodici, J. Yoo, F. Wei, M. Bawendi, F. C. Grozema, M. Sher, T. Buonassisi and J.-P. Correa-Baena, The effect of structural dimensionality on carrier mobility in lead-halide perovskites, J. Mater. Chem. A, 2019, 7, 23949-23957.

44 G. W. P. Adhyaksa, L. W. Veldhuizen, Y. Kuang, S. Brittman, R. E. I. Schropp and E. C. Garnett, Carrier Diffusion Lengths in Hybrid Perovskites: Processing, Composition, Aging, and Surface Passivation Effects, Chem. Mater., 2016, 28, 5259-5263.

45 K. Galkowski, A. Mitioglu, A. Miyata, P. Plochocka, O. Portugall, G. E. Eperon, J. T.-W. Wang, T. Stergiopoulos, S. D. Stranks, H. J. Snaith and R. J. Nicholas, Determination of the exciton binding energy and effective masses for the methylammonium and formamidinium lead tri-halide perovskite family, Energy Environ. Sci., 2015, 9, 962-970.

46 M. Bokdam, T. Sander, A. Stroppa, S. Picozzi, D. D. Sarma, C. Franchini and G. Kresse, Role of Polar Phonons in the Photo Excited State of Metal Halide Perovskites, Sci. Rep., 2016, 6, 28618.

47 A. Miyata, A. Mitioglu, P. Plochocka, O. Portugall, J. T.-W. Wang, S. D. Stranks, H. J. Snaith and R. J. Nicholas, Direct measurement of the exciton binding energy and effective masses for charge carriers in organic-inorganic tri-halide perovskites, Nat. Phys., 2015, 11, 582-587.

48 A. M. Soufiani, F. Huang, P. Reece, R. Sheng, A. Ho-Baillie and M. A. Green, Polaronic exciton binding energy in iodide and bromide organic-inorganic lead halide perovskites, Appl. Phys. Lett., 2015, 107, 231902.

49 Y. Yamada, T. Nakamura, M. Endo, A. Wakamiya and Y. Kanemitsu, Photoelectronic responses in solutionprocessed perovskite $\mathrm{CH}_{3} \mathrm{NH}_{3} \mathrm{PbI}_{3}$ solar cells studied by photoluminescence and photoabsorption spectroscopy, IEEE J. Photovoltaics, 2015, 5, 401-405.

50 N. Sestu, M. Cadelano, V. Sarritzu, F. Chen, D. Marongiu, R. Piras, M. Mainas, F. Quochi, M. Saba, A. Mura and 
G. Bongiovanni, Absorption F-Sum Rule for the Exciton Binding Energy in Methylammonium Lead Halide Perovskites, J. Phys. Chem. Lett., 2015, 6, 4566-4572.

51 M. Saba, M. Cadelano, D. Marongiu, F. Chen, V. Sarritzu, N. Sestu, C. Figus, M. Aresti, R. Piras, A. Geddo Lehmann, C. Cannas, A. Musinu, F. Quochi, A. Mura and G. Bongiovanni, Correlated electron-hole plasma in organometal perovskites, Nat. Commun., 2014, 5, 5049.

52 V. D'Innocenzo, G. Grancini, M. J. P. Alcocer, A. R. S. Kandada, S. D. Stranks, M. M. Lee, G. Lanzani, H. J. Snaith and A. Petrozza, Excitons versus free charges in organo-lead tri-halide perovskites, Nat. Commun., 2014, 5, 3586.

53 A. De Vos, Detailed balance limit of the efficiency of tandem solar cells, J. Phys. D: Appl. Phys., 1980, 13, 839-846.

54 H. X. Dang, K. Wang, M. Ghasemi, M.-C. Tang, M. De Bastiani, E. Aydin, E. Dauzon, D. Barrit, J. Peng, D.-M. Smilgies, S. De Wolf and A. Amassian, Multi-cation Synergy Suppresses Phase Segregation in Mixed-Halide Perovskites, Joule, 2019, 3, 1746-1764.

55 J. Liu, G. Wang, Z. Song, X. He, K. Luo, Q. Ye, C. Liao and J. Mei, $\mathrm{FAPb}_{1-x} \mathrm{Sn}_{x} \mathrm{I}_{3}$ mixed metal halide perovskites with improved light harvesting and stability for efficient planar heterojunction solar cells, J. Mater. Chem. A, 2017, 5, 9097-9106.

56 C. Wehrenfennig, M. Liu, H. J. Snaith, M. B. Johnston and L. M. Herz, Homogeneous emission line broadening in the organo lead halide perovskite $\mathrm{CH}_{3} \mathrm{NH}_{3} \mathrm{PbI}_{3-x} \mathrm{Cl}_{x}, J$. Phys. Chem. Lett., 2014, 5, 1300-1306.

57 U. G. Jong, C. J. Yu, J. S. Ri, N. H. Kim and G. C. Ri, Influence of halide composition on the structural, electronic, and optical properties of mixed $\mathrm{CH}_{3} \mathrm{NH}_{3} \mathrm{~Pb}\left(\mathrm{I}_{1-x} \mathrm{Br}_{x}\right)_{3}$ perovskites calculated using the virtual crystal approximation method, Phys. Rev. B, 2016, 94, 125139.

58 G. E. Eperon, C. E. Beck and H. J. Snaith, Cation exchange for thin film lead iodide perovskite interconversion, Mater. Horiz., 2016, 3, 63-71.

59 Y. Liu, J. Qian, H. Zhang, B. Xu, Y. Zhang, L. Liu, G. Chen and W. Tian, Influence of organic cations on intrinsic properties of lead iodide perovskite solar cells, Org. Electron., 2018, 62, 269-276.

60 J. Dai, Y. Fu, L. H. Manger, M. T. Rea, L. Hwang, R. H. Goldsmith and S. Jin, Carrier Decay Properties of Mixed Cation Formamidinium-Methylammonium Lead Iodide Perovskite $\left[\mathrm{HC}\left(\mathrm{NH}_{2}\right)_{2}\right]_{1-x}\left[\mathrm{CH}_{3} \mathrm{NH}_{3}\right]_{x} \mathrm{PbI}_{3}$ Nanorods, J. Phys. Chem. Lett., 2016, 7, 5036-5043.

61 R. S. Sanchez, V. Gonzalez-Pedro, J.-W. Lee, N.-G. Park, Y. S. Kang, I. Mora-Sero and J. Bisquert, Slow Dynamic Processes in Lead Halide Perovskite Solar Cells. Characteristic Times and Hysteresis, J. Phys. Chem. Lett., 2014, 5, 2357-2363.

62 M. Salado, L. Calio, R. Berger, S. Kazim and S. Ahmad, Influence of the mixed organic cation ratio in lead iodide based perovskite on the performance of solar cells, Phys. Chem. Chem. Phys., 2016, 18, 27148-27157.

63 S. J. Lee, S. S. Shin, J. Im, T. K. Ahn, J. H. Noh, N. J. Jeon, S. Il Seok and J. Seo, Reducing Carrier Density in
Formamidinium Tin Perovskites and Its Beneficial Effects on Stability and Efficiency of Perovskite Solar Cells, ACS Energy Lett., 2018, 3, 46-53.

64 C. C. Stoumpos, C. D. Malliakas and M. G. Kanatzidis, Semiconducting Tin and Lead Iodide Perovskites with Organic Cations: Phase Transitions, High Mobilities, and Near-Infrared Photoluminescent Properties, Inorg. Chem., 2013, 52, 9019-9038.

65 E. Engel and R. M. Dreizler, Density Functional Theory: An Advanced Course, Theor. Math. Phys., 2011, 2011, 499-515.

66 R. G. Parr, Density Functional Theory, Annu. Rev. Phys. Chem., 1983, 34, 631-656.

67 J. P. Perdew, K. Burke and M. Ernzerhof, Generalized Gradient Approximation Made Simple, Phys. Rev. Lett., 1996, 77, 3865-3868.

68 D. M. Ceperley and B. J. Alder, Ground State of the Electron Gas by a Stochastic Method, Phys. Rev. Lett., 1980, 45, 566-569.

69 M. Shishkin and G. Kresse, Self-consistent GW calculations for semiconductors and insulators, Phys. Rev. B: Condens. Matter Mater. Phys., 2007, 75, 235102.

70 M. Van Schilfgaarde, T. Kotani and S. Faleev, Quasiparticle self-consistent GW theory, Phys. Rev. Lett., 2006, 96, 226402.

71 E. Mosconi, P. Umari and F. De Angelis, Electronic and optical properties of $\mathrm{MAPbX}_{3}$ perovskites $(\mathrm{X}=\mathrm{I}, \mathrm{Br}, \mathrm{Cl})$ : A unified DFT and GW theoretical analysis, Phys. Chem. Chem. Phys., 2016, 18, 27158-27164.

72 P. Umari, E. Mosconi and F. De Angelis, Relativistic GW calculations on $\mathrm{CH}_{3} \mathrm{NH}_{3} \mathrm{PbI}_{3}$ and $\mathrm{CH}_{3} \mathrm{NH}_{3} \mathrm{SnI}_{3}$ Perovskites for Solar Cell Applications, Sci. Rep., 2015, 4, 4467.

73 C. Motta, F. El-Mellouhi, S. Kais, N. Tabet, F. Alharbi and S. Sanvito, Revealing the role of organic cations in hybrid halide perovskite $\mathrm{CH}_{3} \mathrm{NH}_{3} \mathrm{PbI}_{3}$, Nat. Commun., 2015, 6, 7026.

74 E. Menéndez-Proupin, P. Palacios, P. Wahnón and J. C. Conesa, Self-consistent relativistic band structure of the $\mathrm{CH}_{3} \mathrm{NH}_{3} \mathrm{PbI}_{3}$ perovskite, Phys. Rev. B: Condens. Matter Mater. Phys., 2014, 90, 045207.

75 M. R. Filip and F. Giustino, GW quasiparticle band gap of the hybrid organic-inorganic perovskite $\mathrm{CH}_{3} \mathrm{NH}_{3} \mathrm{PbI}_{3}$ : Effect of spin-orbit interaction, semicore electrons, and self-consistency, Phys. Rev. B: Condens. Matter Mater. Phys., 2014, 90, 245145.

76 G. Giorgi, J. I. Fujisawa, H. Segawa and K. Yamashita, Cation role in structural and electronic properties of 3D organic-inorganic halide perovskites: A DFT analysis, J. Phys. Chem. C, 2014, 118, 12176-12183.

77 F. Brivio, K. T. Butler, A. Walsh and M. van Schilfgaarde, Relativistic quasiparticle self-consistent electronic structure of hybrid halide perovskite photovoltaic absorbers, Phys. Rev. B: Condens. Matter Mater. Phys., 2014, 89, 155204.

78 G. Strinati, H. J. Mattausch and W. Hanke, Dynamical aspects of correlation corrections in a covalent crystal, Phys. Rev. B: Condens. Matter Mater. Phys., 1982, 25, 2867-2888. 
79 M. S. Hybertsen and S. G. Louie, First-principles theory of quasiparticles: Calculation of band gaps in semiconductors and insulators, Phys. Rev. Lett., 1985, 55, 1418-1421.

80 P. Liu, M. Kaltak, J. Klimeš and G. Kresse, Cubic scaling GW: Towards fast quasiparticle calculations, Phys. Rev. B, 2016, 94, 165109.

81 I. E. Castelli, J. M. García-Lastra, K. S. Thygesen and K. W. Jacobsen, Bandgap calculations and trends of organometal halide perovskites, APL Mater., 2014, 2, 081514.

82 X. Wang, W. Meng and Y. Yan, Electronic band structures and excitonic properties of delafossites: A GW -BSE study, J. Appl. Phys., 2017, 122, 085104.

83 M. L. Tiago and J. R. Chelikowsky, Optical excitations in organic molecules, clusters, and defects studied by first-principles Green's function methods, Phys. Rev. B: Condens. Matter Mater. Phys., 2006, 73, 205334.

84 G. Onida, L. Reining and A. Rubio, Electronic excitations: density-functional versus many-body Green's-function approaches, Rev. Mod. Phys., 2002, 74, 601-659.

85 M. Rohlfing and S. G. Louie, Electron-hole excitations and optical spectra from first principles, Phys. Rev. B: Condens. Matter Mater. Phys., 2000, 62, 4927-4944.

86 M. T. Weller, O. J. Weber, J. M. Frost and A. Walsh, Cubic Perovskite Structure of Black Formamidinium Lead Iodide, $\alpha-\left[\mathrm{HC}\left(\mathrm{NH}_{2}\right)_{2}\right] \mathrm{PbI}_{3}$, at $298 \mathrm{~K}, J$. Phys. Chem. Lett., 2015, 6, 3209-3212.

87 E. C. Schueller, G. Laurita, D. H. Fabini, C. C. Stoumpos, M. G. Kanatzidis and R. Seshadri, Crystal Structure Evolution and Notable Thermal Expansion in Hybrid Perovskites Formamidinium Tin Iodide and Formamidinium Lead Bromide, Inorg. Chem., 2018, 57, 695-701.

88 V. C. A. Taylor, D. Tiwari, M. Duchi, P. M. Donaldson, I. P. Clark, D. J. Fermin and T. A. A. Oliver, Investigating the Role of the Organic Cation in Formamidinium Lead Iodide Perovskite Using Ultrafast Spectroscopy, J. Phys. Chem. Lett., 2018, 9, 895-901.

89 F. Brivio, C. Caetano and A. Walsh, Thermodynamic Origin of Photoinstability in the $\mathrm{CH}_{3} \mathrm{NH}_{3} \mathrm{~Pb}\left(\mathrm{I}_{1-x} \mathrm{Br}_{x}\right)_{3}$ Hybrid Halide Perovskite Alloy, J. Phys. Chem. Lett., 2016, 7, 1083-1087.

90 F. Brivio, J. M. Frost, J. M. Skelton, A. J. Jackson, O. J. Weber, M. T. Weller, A. R. Goñi, A. M. A. Leguy, P. R. F. Barnes and A. Walsh, Lattice dynamics and vibrational spectra of the orthorhombic, tetragonal, and cubic phases of methylammonium lead iodide, Phys. Rev. B: Condens. Matter Mater. Phys., 2015, 92, 144308.

91 J. M. Frost, K. T. Butler, F. Brivio, C. H. Hendon, M. van Schilfgaarde and A. Walsh, Atomistic Origins of HighPerformance in Hybrid Halide Perovskite Solar Cells, Nano Lett., 2014, 14, 2584-2590.

92 G. Kresse and J. Furthmüller, Efficient iterative schemes for ab initio total-energy calculations using a plane-wave basis set, Phys. Rev. B: Condens. Matter Mater. Phys., 1996, 54, 11169-11186.

93 G. Kresse and D. Joubert, From ultrasoft pseudopotentials to the projector augmented-wave method, Phys. Rev. B: Condens. Matter Mater. Phys., 1999, 59, 1758-1775.
94 P. E. Blöchl, Projector augmented-wave method, Phys. Rev. B: Condens. Matter Mater. Phys., 1994, 50, 17953-17979.

95 I. Hamada, van der Waals density functional made accurate, Phys. Rev. B: Condens. Matter Mater. Phys., 2014, 89, 121103.

96 P. Liu, B. Kim, X. Q. Chen, D. D. Sarma, G. Kresse and C. Franchini, Relativistic GW +BSE study of the optical properties of Ruddlesden-Popper iridates, Phys. Rev. Mater., 2018, 2, 75003.

97 P. Liu, C. Franchini, M. Marsman and G. Kresse, Assessing model-dielectric-dependent hybrid functionals on the antiferromagnetic transition-metal monoxides $\mathrm{MnO}, \mathrm{FeO}$, CoO, and NiO, J. Phys.: Condens. Matter, 2020, 32, 015502.

98 G. H. Wannier, The structure of electronic excitation levels in insulating crystals, Phys. Rev., 1937, 52, 191-197.

99 W. Travis, E. N. K. Glover, H. Bronstein, D. O. Scanlon and R. G. Palgrave, On the application of the tolerance factor to inorganic and hybrid halide perovskites: a revised system, Chem. Sci., 2016, 7, 4548-4556.

100 G. Kieslich, S. Sun and A. K. Cheetham, An extended Tolerance Factor approach for organic-inorganic perovskites, Chem. Sci., 2015, 6, 3430-3433.

101 G. Kieslich, S. Sun and A. K. Cheetham, Solid-state principles applied to organic-inorganic perovskites: new tricks for an old dog, Chem. Sci., 2014, 5, 4712-4715.

102 C. Li, X. Lu, W. Ding, L. Feng, Y. Gao and Z. Guo, Formability of $\mathrm{ABX}_{3}(\mathrm{X}=\mathrm{F}, \mathrm{Cl}, \mathrm{Br}, \mathrm{I})$ halide perovskites, Acta Crystallogr., Sect. B: Struct. Sci., 2008, 64, 702-707.

103 A. Perumal, S. Shendre, M. Li, Y. K. E. Tay, V. K. Sharma, S. Chen, Z. Wei, Q. Liu, Y. Gao, P. J. S. Buenconsejo, S. T. Tan, C. L. Gan, Q. Xiong, T. C. Sum and H. V. Demir, High brightness formamidinium lead bromide perovskite nanocrystal light emitting devices, Sci. Rep., 2016, 6, 36733.

104 F. C. Hanusch, E. Wiesenmayer, E. Mankel, A. Binek, P. Angloher, C. Fraunhofer, N. Giesbrecht, J. M. Feckl, W. Jaegermann, D. Johrendt, T. Bein and P. Docampo, Efficient planar heterojunction perovskite solar cells based on formamidinium lead bromide, J. Phys. Chem. Lett., 2014, 5, 2791-2795.

105 M. Pazoki and T. Edvinsson, Metal replacement in perovskite solar cell materials: chemical bonding effects and optoelectronic properties, Sustain, Energy Fuels, 2018, 2, 1430-1445.

106 T. M. Koh, K. Fu, Y. Fang, S. Chen, T. C. Sum, N. Mathews, S. G. Mhaisalkar, P. P. Boix and T. Baikie, FormamidiniumContaining Metal-Halide: An Alternative Material for Near-IR Absorption Perovskite Solar Cells, J. Phys. Chem. C, 2014, 118, 16458-16462.

107 R. Venugopal, P. I. Lin and Y. T. Chen, Photoluminescence and Raman scattering from catalytically grown $\mathrm{Zn}_{x} \mathrm{Cd}_{1-x} \mathrm{Se}$ alloy nanowires, J. Phys. Chem. B, 2006, 110, 11691-11696.

108 R. Hill, Energy-gap variations in semiconductor alloys, J. Phys. C: Solid State Phys., 1974, 7, 521-526.

109 A. A. Mostofi, J. R. Yates, G. Pizzi, Y.-S. Lee, I. Souza, D. Vanderbilt and N. Marzari, An updated version of wannier90: A tool for obtaining maximally-localised Wannier functions, Comput. Phys. Commun., 2014, 185, 2309-2310. 
110 I. Souza, N. Marzari and D. Vanderbilt, Maximally localized Wannier functions for entangled energy bands, Phys. Rev. B: Condens. Matter Mater. Phys., 2001, 65, 035109.

111 T. Etienne, E. Mosconi and F. De Angelis, Dynamical Origin of the Rashba Effect in Organohalide Lead Perovskites: A Key to Suppressed Carrier Recombination in Perovskite Solar Cells?, J. Phys. Chem. Lett., 2016, 7, 1638-1645.

112 E. M. Hutter, M. C. Gélvez-Rueda, A. Osherov, V. Bulović, F. C. Grozema, S. D. Stranks and T. J. Savenije, Directindirect character of the bandgap in methylammonium lead iodide perovskite, Nat. Mater., 2017, 16, 115-120.

113 A. Stroppa, D. Di Sante, P. Barone, M. Bokdam, G. Kresse, C. Franchini, M.-H. Whangbo and S. Picozzi, Tunable ferroelectric polarization and its interplay with spin-orbit coupling in tin iodide perovskites, Nat. Commun., 2014, 5, 5900.

114 M. Baranowski and P. Plochocka, Excitons in Metal-Halide Perovskites, Adv. Energy Mater., 2020, 1903659.

115 T. J. Whitcher, J. X. Zhu, X. Chi, H. Hu, D. Zhao, T. C. Asmara, X. Yu, M. B. H. Breese, A. H. Castro Neto,
Y. M. Lam, A. T. S. Wee, E. E. M. Chia and A. Rusydi, Importance of Electronic Correlations and Unusual Excitonic Effects in Formamidinium Lead Halide Perovskites, Phys. Rev. X, 2018, 8, 1-10.

116 M. Kato, T. Fujiseki, T. Miyadera, T. Sugita, S. Fujimoto, M. Tamakoshi, M. Chikamatsu and H. Fujiwara, Universal rules for visible-light absorption in hybrid perovskite materials, J. Appl. Phys., 2017, 121, 115501.

117 P. F. Ndione, Z. Li and K. Zhu, Effects of alloying on the optical properties of organic-inorganic lead halide perovskite thin films, J. Mater. Chem. C, 2016, 4, 7775-7782.

118 G. Mannino, I. Deretzis, E. Smecca, A. La Magna, A. Alberti, D. Ceratti and D. Cahen, Temperature-Dependent Optical Band Gap in $\mathrm{CsPbBr}_{3}, \mathrm{MAPbBr}_{3}$, and $\mathrm{FAPbBr}_{3}$ Single Crystals, J. Phys. Chem. Lett., 2020, 11, 2490-2496.

119 C. L. Davies, J. Borchert, C. Q. Xia, R. L. Milot, H. Kraus, M. B. Johnston and L. M. Herz, Impact of the Organic Cation on the Optoelectronic Properties of Formamidinium Lead Triiodide, J. Phys. Chem. Lett., 2018, 9, 4502-4511. 